\title{
Three-step Mann iterations for a general system of variational inequalities and an infinite family of nonexpansive mappings in Banach spaces
}

\author{
Lu-Chuan Ceng ${ }^{1,2}$ and Ching-Feng Wen ${ }^{3 *}$
}

*Correspondence:

cfwen@kmu.edu.tw

${ }^{3}$ Center for Fundamental Science,

Kaohsiung Medical University,

Kaohsiung, 807, Taiwan

Full list of author information is

available at the end of the article

\begin{abstract}
In this paper, let $X$ be a uniformly convex Banach space which either is uniformly smooth or has a weakly continuous duality map. We introduce and consider three-step Mann iterations for finding a common solution of a general system of variational inequalities (GSVI) and a fixed point problem (FPP) of an infinite family of nonexpansive mappings in $X$. Here three-step Mann iterations are based on Korpelevich's extragradient method, the viscosity approximation method and the Mann iteration method. We prove the strong convergence of this method to a common solution of the GSVI and the FPP, which solves a variational inequality on their common solution set. We also give a weak convergence theorem for three-step Mann iterations involving the GSVI and the FPP in a Hilbert space. The results presented in this paper improve, extend, supplement and develop the corresponding results announced in the earlier and very recent literature.
\end{abstract}

MSC: 49J30; 47H09; 47J20

Keywords: three-step Mann iterations; general system of variational inequalities; infinitely many nonexpansive mappings; sunny nonexpansive retraction; fixed point; strictly convex Banach space; uniformly smooth Banach space; reflexive Banach space with weakly continuous duality map

\section{Introduction}

Let $X$ be a real Banach space whose dual space is denoted by $X^{*}$. The normalized duality mapping $J: X \rightarrow 2^{X^{*}}$ is defined by

$$
J(x)=\left\{x^{*} \in X^{*}:\left\langle x, x^{*}\right\rangle=\|x\|^{2}=\left\|x^{*}\right\|^{2}\right\}, \quad \forall x \in X,
$$

where $\langle\cdot, \cdot\rangle$ denotes the generalized duality pairing. It is an immediate consequence of the Hahn-Banach theorem that $J(x)$ is nonempty for each $x \in X$. Let $U=\{x \in X:\|x\|=1\}$ denote the unite sphere of $X$. A Banach space $X$ is said to be uniformly convex if for each $\epsilon \in(0,2]$, there exists $\delta>0$ such that for all $x, y \in U$,

$$
\|x-y\| \geq \epsilon \quad \Rightarrow \quad\|x+y\| / 2 \leq 1-\delta .
$$

○2013 Ceng and Wen; licensee Springer. This is an Open Access article distributed under the terms of the Creative Commons Attribution License (http://creativecommons.org/licenses/by/2.0), which permits unrestricted use, distribution, and reproduction in any medium, provided the original work is properly cited. 
It is known that a uniformly convex Banach space is reflexive and strictly convex. A Banach space $X$ is said to be smooth if the limit

$$
\lim _{t \rightarrow 0} \frac{\|x+t y\|-\|x\|}{t}
$$

exists for all $x, y \in U$; in this case, $X$ is also said to have a Gateaux differentiable norm. $X$ is said to have a uniformly Gateaux differentiable norm if for each $y \in U$, the limit is attained uniformly for $x \in U$. Moreover, it is said to be uniformly smooth if this limit is attained uniformly for $x, y \in U$. The norm of $X$ is said to be the Frechet differential if for each $x \in U$, this limit is attained uniformly for $y \in U$.

Let $C$ be a nonempty closed convex subset of $X$, and let $T: C \rightarrow C$ be a nonlinear mapping. Denote by $\operatorname{Fix}(T)$ the set of fixed points of $T$, i.e., $\operatorname{Fix}(T)=\{x \in C: T x=x\}$. Recall that $T$ is nonexpansive if $\|T x-T y\| \leq\|x-y\|$ for all $x, y \in C$. A mapping $f: C \rightarrow C$ is said to be a contraction on $C$ if there exists a constant $\rho$ in $(0,1)$ such that $\|f(x)-f(y)\| \leq \rho\|x-y\|$ for all $x, y \in C$. A mapping $A: C \rightarrow X$ is said to be accretive if for each $x, y \in C$ there exists $j(x-y) \in J(x-y)$ such that $\langle A x-A y, j(x-y)\rangle \geq 0$.

Recently, Yao et al. [1] combined the viscosity approximation method and the Mann iteration method and gave the following hybrid viscosity approximation method.

Let $C$ be a nonempty closed convex subset of a real uniformly smooth Banach space $X$, let $T: C \rightarrow C$ be a nonexpansive mapping such that Fix $(T) \neq \emptyset$ and $f \in \Xi_{C}$ with a contractive coefficient $\rho \in(0,1)$, where $\Xi_{C}$ is the collection of all contractive self-mappings on $C$. For an arbitrary $x_{0} \in C$, define $\left\{x_{n}\right\}$ in the following way:

$$
\left\{\begin{array}{l}
y_{n}=\alpha_{n} x_{n}+\left(1-\alpha_{n}\right) T x_{n}, \\
x_{n+1}=\beta_{n} f\left(x_{n}\right)+\left(1-\beta_{n}\right) y_{n}, \quad \forall n \geq 0,
\end{array}\right.
$$

where $\left\{\alpha_{n}\right\}$ and $\left\{\beta_{n}\right\}$ are two sequences in $(0,1)$. They proved under certain control conditions on the sequences $\left\{\alpha_{n}\right\}$ and $\left\{\beta_{n}\right\}$ that $\left\{x_{n}\right\}$ converges strongly to a fixed point of $T$. Subsequently, Ceng and Yao [2] under the convergence of no parameter sequences to zero proved that the sequence $\left\{x_{n}\right\}$ generated by (YCY) converges strongly to a fixed point of $T$. Such a result includes [1, Theorem 1$]$ as a special case.

Theorem 1.1 (see [2, Theorem 3.1]) Let $C$ be a nonempty closed convex subset of a uniformly smooth Banach space $X$. Let $T: C \rightarrow C$ be a nonexpansive mapping with $\operatorname{Fix}(T) \neq \varnothing$ and $f \in \Xi_{C}$ with a contractive coefficient $\rho \in(0,1)$. Given sequences $\left\{\alpha_{n}\right\}$ and $\left\{\beta_{n}\right\}$ in $[0,1]$, the following control conditions are satisfied:

(i) $0 \leq \beta_{n} \leq 1-\rho, \forall n \geq n_{0}$ for some integer $n_{0} \geq 0$;

(ii) $\sum_{n=0}^{\infty} \beta_{n}=\infty$;

(iii) $0<\liminf _{n \rightarrow \infty} \alpha_{n} \leq \limsup \sup _{n \rightarrow \infty} \alpha_{n}<1$;

(iv) $\lim _{n \rightarrow \infty}\left(\frac{\beta_{n+1}}{1-\left(1-\beta_{n+1}\right) \alpha_{n+1}}-\frac{\beta_{n}}{1-\left(1-\beta_{n}\right) \alpha_{n}}\right)=0$.

For an arbitrary $x_{0} \in C$, let $\left\{x_{n}\right\}$ be generated by (YCY). Then

$$
x_{n} \rightarrow q \quad \Longleftrightarrow \quad \beta_{n}\left(f\left(x_{n}\right)-x_{n}\right) \rightarrow 0,
$$

where $q \in \operatorname{Fix}(T)$ solves the VIP

$$
\langle q-f(q), J(q-p)\rangle \leq 0, \quad \forall p \in \operatorname{Fix}(T) .
$$


Let $C$ be a nonempty closed convex subset of a real Banach space $X$, and $f \in \Xi_{C}$ with a contractive coefficient $\rho \in(0,1)$. Let $\left\{T_{n}\right\}_{n=0}^{\infty}$ be an infinite family of nonexpansive selfmappings on $C$, and let $\left\{\lambda_{n}\right\}_{n=0}^{\infty}$ be a sequence of nonnegative numbers in $[0,1]$. For any $n \geq 0$, define a self-mapping $W_{n}$ on $C$ as follows:

$$
\left\{\begin{array}{l}
U_{n, n+1}=I, \\
U_{n, n}=\lambda_{n} T_{n} U_{n, n+1}+\left(1-\lambda_{n}\right) I, \\
U_{n, n-1}=\lambda_{n-1} T_{n-1} U_{n, n}+\left(1-\lambda_{n-1}\right) I, \\
\ldots, \\
U_{n, k}=\lambda_{k} T_{k} U_{n, k+1}+\left(1-\lambda_{k}\right) I, \\
U_{n, k-1}=\lambda_{k-1} T_{k-1} U_{n, k}+\left(1-\lambda_{k-1}\right) I, \\
\ldots, \\
U_{n, 1}=\lambda_{1} T_{1} U_{n, 2}+\left(1-\lambda_{1}\right) I, \\
W_{n}=U_{n, 0}=\lambda_{0} T_{0} U_{n, 1}+\left(1-\lambda_{0}\right) I .
\end{array}\right.
$$

Such a mapping $W_{n}$ is called the $W$-mapping generated by $T_{n}, T_{n-1}, \ldots, T_{0}$ and $\lambda_{n}, \lambda_{n-1}$, $\ldots, \lambda_{0} ;$ see $[3]$.

In 2012, Ceng et al. [4] introduced and analyzed the following hybrid viscosity approximation method for finding a common fixed point of an infinite family of nonexpansive mappings in a strictly convex and reflexive Banach space, which either is uniformly smooth or has a weakly continuous duality map $J_{\varphi}$ with gauge $\varphi$.

Theorem 1.2 (see [4, Theorem 3.3]) Let $C$ be a nonempty closed convex subset of a reflexive and strictly convex Banach space X. Assume, in addition, that X either is uniformly smooth or has a weakly continuous duality map $J_{\varphi}$ with gauge $\varphi$. Let $\left\{T_{n}\right\}_{n=0}^{\infty}$ be an infinite family of nonexpansive self-mappings on $C$ such that the common fixed point set $F:=\bigcap_{n=0}^{\infty} \operatorname{Fix}\left(T_{n}\right) \neq \emptyset$ and $f \in \Xi_{C}$ with a contractive coefficient $\rho \in(0,1)$. Given sequences $\left\{\alpha_{n}\right\},\left\{\beta_{n}\right\}$ and $\left\{\lambda_{n}\right\}$ in $[0,1]$, the following conditions are satisfied:

(i) $0 \leq \beta_{n} \leq 1-\rho, \forall n \geq n_{0}$ for some $n_{0} \geq 0$, and $\sum_{n=0}^{\infty} \beta_{n}=\infty$;

(ii) $0<\liminf _{n \rightarrow \infty} \alpha_{n} \leq \limsup _{n \rightarrow \infty} \alpha_{n}<1$;

(iii) $\lim _{n \rightarrow \infty}\left(\frac{\left.\beta_{n+1}\right)}{1-\left(1-\beta_{n+1}\right) \alpha_{n+1}}-\frac{\beta_{n}}{1-\left(1-\beta_{n}\right) \alpha_{n}}\right)=0$;

(iv) $0<\lambda_{n} \leq b<1, \forall n \geq 0$ for some constant $b \in(0,1)$.

For an arbitrary $x_{0} \in C$, let $\left\{x_{n}\right\}$ be generated by

$$
\left\{\begin{array}{l}
y_{n}=\alpha_{n} x_{n}+\left(1-\alpha_{n}\right) W_{n} x_{n}, \\
x_{n+1}=\beta_{n} f\left(x_{n}\right)+\left(1-\beta_{n}\right) y_{n}, \quad \forall n \geq 0,
\end{array}\right.
$$

where $W_{n}$ is the $W$-mapping generated by $T_{n}, T_{n-1}, \ldots, T_{0}$ and $\lambda_{n}, \lambda_{n-1}, \ldots, \lambda_{0}$. Then

$$
x_{n} \rightarrow q \in F \quad \Longleftrightarrow \quad \beta_{n}\left(f\left(x_{n}\right)-x_{n}\right) \rightarrow 0 .
$$

In this case, 
(i) if $X$ is uniformly smooth, then $q \in F$ solves the VIP

$$
\langle q-f(q), J(q-p)\rangle, \quad \forall p \in F
$$

(ii) if $X$ has a weakly continuous duality map $J_{\varphi}$ with gauge $\varphi$, then $q \in F$ solves the VIP

$$
\left\langle q-f(q), J_{\varphi}(q-p)\right\rangle, \quad \forall p \in F
$$

On the other hand, $\mathrm{Cai}$ and $\mathrm{Bu}$ [5] considered the following general system of variational inequalities (GSVI) in a real smooth Banach space $X$, which involves finding $\left(x^{*}, y^{*}\right) \in$ $C \times C$ such that

$$
\begin{cases}\left\langle\mu_{1} B_{1} y^{*}+x^{*}-y^{*}, J\left(x-x^{*}\right)\right\rangle \geq 0, & \forall x \in C, \\ \left\langle\mu_{2} B_{2} x^{*}+y^{*}-x^{*}, J\left(x-y^{*}\right)\right\rangle \geq 0, & \forall x \in C,\end{cases}
$$

where $C$ is a nonempty, closed and convex subset of $X, B_{1}, B_{2}: C \rightarrow X$ are two nonlinear mappings and $\mu_{1}$ and $\mu_{2}$ are two positive constants. Here, the set of solutions of GSVI (1.1) is denoted by $\operatorname{GSVI}\left(C, B_{1}, B_{2}\right)$. In particular, if $X=H$, a real Hilbert space, then GSVI (1.1) reduces to the following GSVI of finding $\left(x^{*}, y^{*}\right) \in C \times C$ such that

$$
\begin{cases}\left\langle\mu_{1} B_{1} y^{*}+x^{*}-y^{*}, x-x^{*}\right\rangle \geq 0, & \forall x \in C, \\ \left\langle\mu_{2} B_{2} x^{*}+y^{*}-x^{*}, x-y^{*}\right\rangle \geq 0, & \forall x \in C,\end{cases}
$$

which is studied in Ceng et al. [6]. The set of solutions of problem (1.2) is still denoted by $\operatorname{GSVI}\left(C, B_{1}, B_{2}\right)$. In particular, if $B_{1}=B_{2}=A$, then problem (1.2) reduces to the new system of variational inequalities (NSVI), introduced and studied by Verma [7]. Further, if $x^{*}=y^{*}$ additionally, then the NSVI reduces to the classical variational inequality problem (VIP) of finding $x^{*} \in C$ such that

$$
\left\langle A x^{*}, x-x^{*}\right\rangle \geq 0, \quad \forall x \in C
$$

The solution set of VIP (1.3) is denoted by $\operatorname{VI}(C, A)$. Variational inequality theory has been studied quite extensively and has emerged as an important tool in the study of a wide class of obstacle, unilateral, free, moving, equilibrium problems. It is now well known that the variational inequalities are equivalent to the fixed point problems, the origin of which can be traced back to Lions and Stampacchia [8]. This alternative formulation has been used to suggest and analyze the projection iterative method for solving variational inequalities under the conditions that the involved operator must be strongly monotone and Lipschitz continuous.

In 1976, Korpelevich [9] proposed an iterative algorithm for solving VIP (1.3) in Euclidean space $\mathbf{R}^{n}$ :

$$
\left\{\begin{array}{l}
y_{n}=P_{C}\left(x_{n}-\tau A x_{n}\right), \\
x_{n+1}=P_{C}\left(x_{n}-\tau A y_{n}\right), \quad \forall n \geq 0,
\end{array}\right.
$$


with $\tau>0$ a given number, which is known as the extragradient method (see also [10,11]). The literature on the VIP is vast and Korpelevich's extragradient method has received great attention from many authors, who improved it in various ways; see, e.g., $[5,8,12-29]$ and references therein, to name but a few.

In particular, whenever $X$ is still a real smooth Banach space, $B_{1}=B_{2}=A$ and $x^{*}=y^{*}$, then GSVI (1.1) reduces to the variational inequality problem (VIP) of finding $x^{*} \in C$ such that

$$
\left\langle A x^{*}, J\left(x-x^{*}\right)\right\rangle \geq 0, \quad \forall x \in C,
$$

which was considered by Aoyama et al. [30]. Note that VIP (1.5) is connected with the fixed point problem for a nonlinear mapping (see, e.g., [31]), the problem of finding a zero point of a nonlinear operator (see, e.g., [32]) and so on. It is clear that VIP (1.5) extends VIP (1.3) from Hilbert spaces to Banach spaces.

In order to find a solution of VIP (1.5), Aoyama et al. [30] introduced the following Mann iterative scheme for an accretive operator $A$ :

$$
x_{n+1}=\alpha_{n} x_{n}+\left(1-\alpha_{n}\right) \Pi_{C}\left(x_{n}-\lambda_{n} A x_{n}\right), \quad \forall n \geq 1,
$$

where $\Pi_{C}$ is a sunny nonexpansive retraction from $X$ onto $C$. Then they proved a weak convergence theorem. For related work, please see [33] and the references therein.

Beyond doubt, it is an interesting and valuable problem of constructing some algorithms with strong convergence for solving GSVI (1.1) which contains VIP (1.5) as a special case. Very recently, Cai and $\mathrm{Bu}$ [5] constructed an iterative algorithm for solving GSVI (1.1) and a fixed point problem of an infinite family of nonexpansive mappings in a uniformly convex and 2-uniformly smooth Banach space. They proved the strong convergence of the proposed algorithm by virtue of the following inequality in a 2-uniformly smooth Banach space $X$.

Lemma 1.1 (see [34]) Let X be a 2-uniformly smooth Banach space. Then

$$
\|x+y\|^{2} \leq\|x\|^{2}+2\langle y, J(x)\rangle+2\|\kappa y\|^{2}, \quad \forall x, y \in X
$$

where $\kappa$ is the 2-uniformly smooth constant of $X$ and $J$ is the normalized duality mapping from $X$ into $X^{*}$.

Theorem 1.3 (see [5, Theorem 3.1]) Let $C$ be a nonempty closed convex subset of a uniformly convex and 2-uniformly smooth Banach space $X$. Let $\Pi_{C}$ be a sunny nonexpansive retraction from $X$ onto $C$. Let the mapping $B_{i}: C \rightarrow X$ be $\beta_{i}$-inverse-strongly accretive with $0<\mu_{i}<\frac{\beta_{i}}{\kappa^{2}}$ for $i=1,2$. Let $f$ be a contraction of $C$ into itself with a coefficient $\rho \in(0,1)$. Let $\left\{T_{n}\right\}_{n=1}^{\infty}$ be an infinite family of nonexpansive mappings of $C$ into itself such that $F=\bigcap_{i=1}^{\infty} \operatorname{Fix}\left(T_{i}\right) \cap \Omega \neq \emptyset$, where $\Omega$ is a fixed point set of the mapping $G:=\Pi_{C}\left(I-\mu_{1} B_{1}\right) \Pi_{C}\left(I-\mu_{2} B_{2}\right)$. For arbitrarily given $x_{1} \in C$, let $\left\{x_{n}\right\}$ be a sequence generated by

$$
\left\{\begin{array}{l}
y_{n}=\alpha_{n} f\left(x_{n}\right)+\left(1-\alpha_{n}\right) G x_{n}, \\
x_{n+1}=\beta_{n} x_{n}+\left(1-\beta_{n}\right) T_{n} y_{n}, \quad \forall n \geq 1 .
\end{array}\right.
$$


Suppose that $\left\{\alpha_{n}\right\}$ and $\left\{\beta_{n}\right\}$ are two sequences in $(0,1)$ satisfying the following conditions:

(i) $\lim _{n \rightarrow \infty} \alpha_{n}=0$ and $\sum_{n=1}^{\infty} \alpha_{n}=\infty$;

(ii) $0<\liminf _{n \rightarrow \infty} \beta_{n} \leq \limsup _{n \rightarrow \infty} \beta_{n}<1$.

Assume that $\sum_{n=1}^{\infty} \sup _{x \in D}\left\|T_{n+1} x-T_{n} x\right\|<\infty$ for any bounded subset $D$ of $C$, and let $T$ be a mapping of $C$ into $X$ defined by $T x=\lim _{n \rightarrow \infty} T_{n} x$ for all $x \in C$ and suppose that $\operatorname{Fix}(T)=$ $\bigcap_{n=1}^{\infty} \operatorname{Fix}\left(T_{n}\right)$. Then $\left\{x_{n}\right\}$ converges strongly to $q \in F$, which solves the following VIP:

$$
\langle q-f(q), J(q-p)\rangle \leq 0, \quad \forall p \in F .
$$

For the convenience of implementing the argument techniques in [6], the authors [5] used the following inequality in a real smooth and uniform convex Banach space $X$.

Proposition 1.1 (see [35]) Let X be a real smooth and uniform convex Banach space, and let $r>0$. Then there exists a strictly increasing, continuous and convex function $g:[0,2 r] \rightarrow$ $\mathbf{R}, g(0)=0$ such that

$$
g(\|x-y\|) \leq\|x\|^{2}-2\langle x, J(y)\rangle+\|y\|^{2}, \quad \forall x, y \in B_{r}
$$

where $B_{r}=\{x \in X:\|x\| \leq r\}$.

In this paper, let $X$ be a uniformly convex Banach space which either is uniformly smooth or has a weakly continuous duality map. Let $C$ be a nonempty closed convex subset of $X$, $\Pi_{C}$ be a sunny nonexpansive retraction from $X$ onto $C$ and $f \in \Xi_{C}$ with a contractive coefficient $\rho \in(0,1)$. Motivated and inspired by the research going on in this area, we introduce and analyze three-step Mann iterations for finding a common solution of GSVI (1.1) and a fixed point problem (FPP) of an infinite family of nonexpansive self-mappings on $C$. Here, three-step Mann iterations are based on Korpelevich's extragradient method, the viscosity approximation method and the Mann iteration method. We prove the strong convergence of this method to a common solution of GSVI (1.1) and the FPP, which solves a variational inequality on their common solution set. We also give a weak convergence theorem for three-step Mann iterations involving GSVI (1.2) and the FPP in the case of $X=H$, a Hilbert space. The results presented in this paper improve, extend, supplement and develop the corresponding results announced in the earlier and very recent literature; see, e.g., $[2,4-6,29]$.

\section{Preliminaries}

Let $X$ be a real Banach space. We define a function $\rho:[0, \infty) \rightarrow[0, \infty)$ called the modulus of smoothness of $X$ as follows:

$$
\rho(\tau)=\sup \left\{\frac{1}{2}(\|x+y\|+\|x-y\|)-1: x, y \in X,\|x\|=1,\|y\|=\tau\right\} .
$$

It is known that $X$ is uniformly smooth if and only if $\lim _{\tau \rightarrow 0} \rho(\tau) / \tau=0$. Let $q$ be a fixed real number with $1<q \leq 2$. Then a Banach space $X$ is said to be $q$-uniformly smooth if there exists a constant $c>0$ such that $\rho(\tau) \leq c \tau^{q}$ for all $\tau>0$. As pointed out in [36], no Banach space is $q$-uniformly smooth for $q>2$. In addition, it is also known that $J$ is single-valued if and only if $X$ is smooth, whereas if $X$ is uniformly smooth, then the mapping $J$ is normto-norm uniformly continuous on bounded subsets of $X$. If $X$ has a uniformly Gateaux 
differentiable norm, then the duality mapping $J$ is norm-to-weak* uniformly continuous on bounded subsets of $X$. We use the notation $\rightarrow$ to indicate the weak convergence and $\rightarrow$ to indicate the strong convergence.

Let $C$ be a nonempty closed convex subset of $X$. Recall that a mapping $A: C \rightarrow X$ is said to be

(i) $\alpha$-strongly accretive if for each $x, y \in C$, there exists $j(x-y) \in J(x-y)$ such that

$$
\langle A x-A y, j(x-y)\rangle \geq \alpha\|x-y\|^{2}
$$

for some $\alpha \in(0,1)$;

(ii) $\beta$-inverse-strongly-accretive if for each $x, y \in C$, there exists $j(x-y) \in J(x-y)$ such that

$$
\langle A x-A y, j(x-y)\rangle \geq \beta\|A x-A y\|^{2}
$$

for some $\beta>0$;

(iii) $\lambda$-strictly pseudocontractive [37] (see also [38]) if for each $x, y \in C$, there exists $j(x-y) \in J(x-y)$ such that

$$
\langle A x-A y, j(x-y)\rangle \leq\|x-y\|^{2}-\lambda\|x-y-(A x-A y)\|^{2}
$$

for some $\lambda \in(0,1)$.

It is worth emphasizing that the definition of the inverse strongly accretive mapping is based on that of the inverse strongly monotone mapping, which was studied by so many authors; see, e.g., [17, 39, 40].

We list some lemmas that will be used in the sequel. Lemma 2.1 can be found in [41]. Lemma 2.2 is an immediate consequence of the subdifferential inequality of the function $\frac{1}{2}\|\cdot\|^{2}$.

Lemma 2.1 Let $\left\{s_{n}\right\}$ be a sequence of nonnegative real numbers satisfying the condition

$$
s_{n+1} \leq\left(1-\mu_{n}\right) s_{n}+\mu_{n} v_{n}, \quad \forall n \geq 0,
$$

where $\left\{\mu_{n}\right\}$ and $\left\{v_{n}\right\}$ are sequences of real numbers such that

(i) $\left\{\mu_{n}\right\} \subset[0,1]$ and $\sum_{n=0}^{\infty} \mu_{n}=\infty$, or equivalently,

$$
\prod_{n=0}^{\infty}\left(1-\mu_{n}\right):=\lim _{n \rightarrow \infty} \prod_{k=0}^{n}\left(1-\mu_{k}\right)=0
$$

(ii) $\lim \sup _{n \rightarrow \infty} v_{n} \leq 0$, or $\sum_{n=0}^{\infty} \mu_{n}\left|v_{n}\right|<\infty$.

Then $\lim \sup _{n \rightarrow \infty} s_{n}=0$.

Lemma 2.2 (see [42]) Let $X$ be a real Banach space and J be the normalized duality map on $X$. Then, for any given $x, y \in X$, the following inequality holds:

$$
\|x+y\|^{2} \leq\|x\|^{2}+2\langle y, j(x+y)\rangle, \quad \forall j(x+y) \in J(x+y) .
$$


Let $D$ be a subset of $C$, and let $\Pi$ be a mapping of $C$ into $D$. Then $\Pi$ is said to be sunny if

$$
\Pi[\Pi(x)+t(x-\Pi(x))]=\Pi(x)
$$

whenever $\Pi(x)+t(x-\Pi(x)) \in C$ for $x \in C$ and $t \geq 0$. A mapping $\Pi$ of $C$ into itself is called a retraction if $\Pi^{2}=\Pi$.If a mapping $\Pi$ of $C$ into itself is a retraction, then $\Pi(z)=z$ for every $z \in R(\Pi)$, where $R(\Pi)$ is the range of $\Pi$. A subset $D$ of $C$ is called a sunny nonexpansive retract of $C$ if there exists a sunny nonexpansive retraction from $C$ onto $D$.

The following lemma concerns the sunny nonexpansive retraction.

Lemma 2.3 (see [43]) Let $C$ be a nonempty closed convex subset of a real smooth Banach space $X$. Let $D$ be a nonempty subset of $C$. Let $\Pi$ be a retraction of $C$ onto $D$. Then the following are equivalent:

(i) $\Pi$ is sunny and nonexpansive;

(ii) $\|\Pi(x)-\Pi(y)\|^{2} \leq\langle x-y, J(\Pi(x)-\Pi(y))\rangle, \forall x, y \in C$;

(iii) $\langle x-\Pi(x), J(y-\Pi(x))\rangle \leq 0, \forall x \in C, y \in D$.

It is well known that if $X=H$, a Hilbert space, then a sunny nonexpansive retraction $\Pi_{C}$ is coincident with the metric projection from $X$ onto $C$; that is, $\Pi_{C}=P_{C}$. If $C$ is a nonempty closed convex subset of a strictly convex and uniformly smooth Banach space $X$ and if $T: C \rightarrow C$ is a nonexpansive mapping with the fixed point set $\operatorname{Fix}(T) \neq \emptyset$, then the set $\operatorname{Fix}(T)$ is a sunny nonexpansive retract of $C$.

Lemma 2.4 Let $C$ be a nonempty closed convex subset of a smooth Banach space $X$. Let $\Pi_{C}$ be a sunny nonexpansive retraction from $X$ onto $C$, and let $B_{1}, B_{2}: C \rightarrow X$ be nonlinear mappings. For given $x^{*}, y^{*} \in C,\left(x^{*}, y^{*}\right)$ is a solution of GSVI (1.1) if and only if $x^{*}=\Pi_{C}\left(y^{*}-\right.$ $\left.\mu_{1} B_{1} y^{*}\right)$, where $y^{*}=\Pi_{C}\left(x^{*}-\mu_{2} B_{2} x^{*}\right)$.

Proof We can rewrite GSVI (1.1) as

$$
\begin{cases}\left\langle x^{*}-\left(y^{*}-\mu_{1} B_{1} y^{*}\right), J\left(x-x^{*}\right)\right\rangle \geq 0, & \forall x \in C, \\ \left\langle y^{*}-\left(x^{*}-\mu_{2} B_{2} x^{*}\right), J\left(x-y^{*}\right)\right\rangle \geq 0, & \forall x \in C,\end{cases}
$$

which is obviously equivalent to

$$
\left\{\begin{array}{l}
x^{*}=\Pi_{C}\left(y^{*}-\mu_{1} B_{1} y^{*}\right) \\
y^{*}=\Pi_{C}\left(x^{*}-\mu_{2} B_{2} x^{*}\right)
\end{array}\right.
$$

because of Lemma 2.3. This completes the proof.

In terms of Lemma 2.4, we observe that

$$
x^{*}=\Pi_{C}\left[\Pi_{C}\left(x^{*}-\mu_{2} B_{2} x^{*}\right)-\mu_{1} B_{1} \Pi_{C}\left(x^{*}-\mu_{2} B_{2} x^{*}\right)\right],
$$

which implies that $x^{*}$ is a fixed point of the mapping $G$. Throughout this paper, the set of fixed points of the mapping $G$ is denoted by $\Omega$. 
Lemma 2.5 (see [44]) Let $X$ be a uniformly smooth Banach space, $C$ be a nonempty closed convex subset of $X, T: C \rightarrow C$ be a nonexpansive mapping with $\operatorname{Fix}(T) \neq \emptyset$, and $f \in \Xi_{C}$. Then the net $\left\{x_{t}\right\}$ defined by $x_{t}=t f\left(x_{t}\right)+(1-t) T x_{t}, \forall t \in(0,1)$, converges strongly to a point in $\operatorname{Fix}(T)$. If we define a mapping $Q: \Xi_{C} \rightarrow \operatorname{Fix}(T)$ by $Q(f):=s-\lim _{t \rightarrow 0} x_{t}, \forall f \in \Xi_{C}$, then $Q(f)$ solves the VIP

$$
\langle(I-f) Q(f), J(Q(f)-p)\rangle \leq 0, \quad \forall p \in \operatorname{Fix}(T) .
$$

In particular, if $f=u \in C$ is a constant, then the map $u \mapsto Q(u)$ is reduced to the sunny nonexpansive retraction of Reich type from $C$ onto $\operatorname{Fix}(T)$, i.e.,

$$
\langle Q(u)-u, J(Q(u)-p)\rangle \leq 0, \quad \forall p \in \operatorname{Fix}(T) .
$$

Recall that a gauge is a continuous strictly increasing function $\varphi:[0, \infty) \rightarrow[0, \infty)$ such that $\varphi(0)=0$ and $\varphi(t) \rightarrow \infty$ as $t \rightarrow \infty$. Associated to the gauge $\varphi$ is the duality map $J_{\varphi}$ : $X \rightarrow 2^{X^{*}}$ defined by

$$
J_{\varphi}(x)=\left\{x^{*} \in X^{*}:\left\langle x, x^{*}\right\rangle=\|x\| \varphi(\|x\|),\left\|x^{*}\right\|=\varphi(\|x\|)\right\}, \quad \forall x \in X .
$$

We say that a Banach space $X$ has a weakly continuous duality map if there exists a gauge $\varphi$ for which the duality map $J_{\varphi}$ is single-valued and weak-to-weak* sequentially continuous. It is known that $l^{p}$ has a weakly continuous duality map with gauge $\varphi(t)=t^{p-1}$ for all $1<$ $p<\infty$. Set

$$
\Phi(t)=\int_{0}^{t} \varphi(\tau) d \tau, \quad \forall t \geq 0
$$

Then $J_{\varphi}(x)=\partial \Phi(\|x\|)$ for all $x \in X$, where $\partial$ denotes the subdifferential in the sense of convex analysis; see [42] for more details.

The first part of the following lemma is an immediate consequence of the subdifferential inequality, and the proof of the second part can be found in [45].

Lemma 2.6 Assume that $X$ has a weakly continuous duality map $J_{\varphi}$ with gauge $\varphi$.

(i) For all $x, y \in X$, the following inequality holds:

$$
\Phi(\|x+y\|) \leq \Phi(\|x\|)+\left\langle y, J_{\varphi}(x+y)\right\rangle .
$$

(ii) Assume that a sequence $\left\{x_{n}\right\}$ in $X$ is weakly convergent to a point $x$. Then the following identity holds:

$$
\limsup _{n \rightarrow \infty} \Phi\left(\left\|x_{n}-y\right\|\right)=\limsup _{n \rightarrow \infty} \Phi\left(\left\|x_{n}-x\right\|\right)+\Phi(\|y-x\|), \quad \forall y \in X
$$

Lemma 2.7 ([31, Theorem 3.1 and its proof $]$ ) Let $X$ be a reflexive Banach space and have a weakly continuous duality map $J_{\varphi}$ with gauge $\varphi$, let $C$ be a nonempty closed convex subset of $X$, let $T: C \rightarrow C$ be a nonexpansive mapping with $\operatorname{Fix}(T) \neq \emptyset$, and let $f \in \Xi_{C}$. Then $\left\{x_{t}\right\}$ defined by $x_{t}=t f\left(x_{t}\right)+(1-t) T x_{t}, \forall t \in(0,1)$, converges strongly to a point in $\operatorname{Fix}(T)$ as 
$t \rightarrow 0^{+}$. Define $Q: \Xi_{C} \rightarrow \operatorname{Fix}(T)$ by $Q(f):=s-\lim _{t \rightarrow 0^{+}} x_{t}$. Then $Q(f)$ solves the variational inequality

$$
\left\langle(I-f) Q(f), J_{\varphi}(Q(f)-p)\right\rangle \leq 0, \quad \forall p \in \operatorname{Fix}(T) .
$$

In particular, if $f=u \in C$ is a constant, then the map $u \mapsto Q(u)$ is reduced to the sunny nonexpansive retraction of Reich type from $C$ onto $\operatorname{Fix}(T)$, i.e.,

$$
\left\langle Q(u)-u, J_{\varphi}(Q(u)-p)\right\rangle \leq 0, \quad \forall p \in \operatorname{Fix}(T) .
$$

Recall that $X$ satisfies Opial's property [46] provided, for each sequence $\left\{x_{n}\right\}$ in $X$, the condition $x_{n} \rightarrow x$ implies

$$
\limsup _{n \rightarrow \infty}\left\|x_{n}-x\right\|<\limsup _{n \rightarrow \infty}\left\|x_{n}-y\right\|, \quad \forall y \in X, y \neq x .
$$

It is known in [46] that each $l^{p}(1 \leq p<\infty)$ enjoys this property, while $L^{p}$ does not unless $p=2$. It is known in [47] that every separable Banach space can be equivalently renormed so that it satisfies Opial's property. We denote by $\omega_{w}\left(x_{n}\right)$ the weak $\omega$-limit set of $\left\{x_{n}\right\}$, i.e.,

$$
\omega_{w}\left(x_{n}\right)=\left\{\bar{x} \in X: x_{n_{i}}-\bar{x} \text { for some subsequence }\left\{x_{n_{i}}\right\} \text { of }\left\{x_{n}\right\}\right\} .
$$

Also, recall that in a Hilbert space $H$, the following equality holds:

$$
\|\lambda x+(1-\lambda) y\|^{2}=\lambda\|x\|^{2}+(1-\lambda)\|y\|^{2}-\lambda(1-\lambda)\|x-y\|^{2}, \quad \forall x, y \in H, \forall \lambda \in[0,1] .
$$

Lemma 2.8 (see [48]) Let $C$ be a nonempty closed convex subset of a strictly convex Banach space $X$. Let $\left\{T_{n}\right\}_{n=0}^{\infty}$ be a sequence of nonexpansive mappings on $C$. Suppose that $\bigcap_{n=0}^{\infty} \operatorname{Fix}\left(T_{n}\right)$ is nonempty. Let $\left\{\lambda_{n}\right\}$ be a sequence of positive numbers with $\sum_{n=0}^{\infty} \lambda_{n}=1$. Then a mapping $S$ on $C$ defined by $S x=\sum_{n=0}^{\infty} \lambda_{n} T_{n} x$ for $x \in C$ is defined well, nonexpansive and $\operatorname{Fix}(S)=\bigcap_{n=0}^{\infty} \operatorname{Fix}\left(T_{n}\right)$ holds.

Lemma 2.9 (see [30]) Let $C$ be a nonempty closed convex subset of a smooth Banach space $X$. Let $\Pi_{C}$ be a sunny nonexpansive retraction from $X$ onto $C$, and let $A: C \rightarrow X$ be an accretive mapping. Then, for all $\lambda>0$,

$$
\operatorname{VI}(C, A)=\operatorname{Fix}\left(\Pi_{C}(I-\lambda A)\right) .
$$

Lemma 2.10 (see [49, Lemma 3.2]) Let C be a nonempty closed convex subset of a strictly convex Banach space X. Let $\left\{T_{n}\right\}_{n=0}^{\infty}$ be a sequence of nonexpansive self-mappings on $C$ such that $\bigcap_{n=0}^{\infty} \operatorname{Fix}\left(T_{n}\right) \neq \emptyset$, and let $\left\{\lambda_{n}\right\}_{n=0}^{\infty}$ be a sequence of positive numbers in $(0, b]$ for some $b \in(0,1)$. Then, for every $x \in C$ and $k \geq 0$, the limit $\lim _{n \rightarrow \infty} U_{n, k} x$ exists.

Using Lemma 2.10, one can define a mapping $W: C \rightarrow C$ as follows:

$$
W x=\lim _{n \rightarrow \infty} W_{n} x=\lim _{n \rightarrow \infty} U_{n, 0} x, \quad \forall x \in C .
$$


Such $W$ is called the $W$-mapping generated by the sequences $\left\{T_{n}\right\}_{n=0}^{\infty}$ and $\left\{\lambda_{n}\right\}_{n=0}^{\infty}$. Throughout this paper, we always assume that $\left\{\lambda_{n}\right\}_{n=0}^{\infty}$ is a sequence of positive numbers in $(0, b]$ for some $b \in(0,1)$.

Lemma 2.11 (see [49, Lemma 3.3]) Let $C$ be a nonempty closed convex subset of a strictly convex Banach space X. Let $\left\{T_{n}\right\}_{n=0}^{\infty}$ be a sequence of nonexpansive self-mappings on C such that $\bigcap_{n=0}^{\infty} \operatorname{Fix}\left(T_{n}\right) \neq \emptyset$, and let $\left\{\lambda_{n}\right\}_{n=0}^{\infty}$ be a sequence of positive numbers in $(0, b]$ for some $b \in(0,1)$. Then $\operatorname{Fix}(W)=\bigcap_{n=0}^{\infty} \operatorname{Fix}\left(T_{n}\right)$.

Lemma 2.12 (see [50, Lemma 2]) Let $\left\{x_{n}\right\}$ and $\left\{z_{n}\right\}$ be bounded sequences in a Banach space $X$, and let $\left\{\beta_{n}\right\}$ be a sequence of nonnegative numbers in $[0,1]$ with $0<$ $\liminf _{n \rightarrow \infty} \beta_{n} \leq \limsup _{n \rightarrow \infty} \beta_{n}<1$. Suppose that $x_{n+1}=\beta_{n} x_{n}+\left(1-\beta_{n}\right) z_{n}$ for all integers $n \geq 0$ and $\limsup _{n \rightarrow \infty}\left(\left\|z_{n+1}-z_{n}\right\|-\left\|x_{n+1}-x_{n}\right\|\right) \leq 0$. Then $\lim _{n \rightarrow \infty}\left\|x_{n}-z_{n}\right\|=0$.

Lemma 2.13 (see [34]) Given a number $r>0$. A real Banach space $X$ is uniformly convex if and only if there exists a continuous strictly increasing function $g:[0, \infty) \rightarrow[0, \infty), g(0)=$ 0 such that

$$
\|\lambda x+(1-\lambda) y\|^{2} \leq \lambda\|x\|^{2}+(1-\lambda)\|y\|^{2}-\lambda(1-\lambda) g(\|x-y\|)
$$

for all $\lambda \in[0,1]$ and $x, y \in X$ such that $\|x\| \leq r$ and $\|y\| \leq r$.

We will also use the following elementary lemmas in the sequel.

Lemma 2.14 (see [51]) Let $\left\{a_{n}\right\}$ and $\left\{b_{n}\right\}$ be the sequences of nonnegative real numbers such that $\sum_{n=0}^{\infty} b_{n}<\infty$ and $a_{n+1} \leq a_{n}+b_{n}$ for all $n \geq 0$. Then $\lim _{n \rightarrow \infty} a_{n}$ exists.

Lemma 2.15 (Demiclosedness principle [42]) Assume that $T$ is a nonexpansive selfmapping of a nonempty closed convex subset $C$ of a Hilbert space $H$. If $T$ has a fixed point, then $I-T$ is demiclosed. That is, whenever $x_{n} \rightarrow x$ in $C$ and $(I-T) x_{n} \rightarrow y$ in $H$, it follows that $(I-T) x=y$. Here, $I$ is the identity operator of $H$.

\section{Main results}

In this section, in order to prove our main results, we will use the following useful lemmas whose proofs will be omitted since they can be proved by standard arguments.

Lemma 3.1 Let $C$ be a nonempty closed convex subset of a smooth Banach space $X$, and let the mapping $B_{i}: C \rightarrow X$ be $\zeta_{i}$-strictly pseudocontractive and $\eta_{i}$-strongly accretive with $\zeta_{i}+\eta_{i} \geq 1$ for $i=1,2$. Then, for $\mu_{i} \in(0,1]$, we have

$$
\left\|\left(I-\mu_{i} B_{i}\right) x-\left(I-\mu_{i} B_{i}\right) y\right\| \leq\left\{\sqrt{\frac{1-\eta_{i}}{\zeta_{i}}}+\left(1-\mu_{i}\right)\left(1+\frac{1}{\zeta_{i}}\right)\right\}\|x-y\|, \quad \forall x, y \in C
$$

for $i=1$, 2. In particular, if $1-\frac{\zeta_{i}}{1+\zeta_{i}}\left(1-\sqrt{\frac{1-\eta_{i}}{\zeta_{i}}}\right) \leq \mu_{i} \leq 1$, then $I-\mu_{i} B_{i}$ is nonexpansive for $i=1,2$. 
Lemma 3.2 Let $C$ be a nonempty closed convex subset of a smooth Banach space X. Let $\Pi_{C}$ be a sunny nonexpansive retraction from $X$ onto $C$, and let the mapping $B_{i}: C \rightarrow X$ be $\zeta_{i}$-strictly pseudocontractive and $\eta_{i}$-strongly accretive with $\zeta_{i}+\eta_{i} \geq 1$ for $i=1,2$. Let $G: C \rightarrow C$ be the mapping defined by

$$
G(x)=\Pi_{C}\left[\Pi_{C}\left(x-\mu_{2} B_{2} x\right)-\mu_{1} B_{1} \Pi_{C}\left(x-\mu_{2} B_{2} x\right)\right], \quad \forall x \in C .
$$

If $1-\frac{\zeta_{i}}{1+\zeta_{i}}\left(1-\sqrt{\frac{1-\eta_{i}}{\zeta_{i}}}\right) \leq \mu_{i} \leq 1$, then $G: C \rightarrow C$ is nonexpansive.

We now state and prove the main result of this paper.

Theorem 3.1 Let $C$ be a nonempty closed convex subset of a uniformly convex Banach space $X$. Assume, in addition, that $X$ either is uniformly smooth or has a weakly continuous duality map $J_{\varphi}$ with gauge $\varphi$. Let $\Pi_{C}$ be a sunny nonexpansive retraction from $X$ onto $C$. Let the mapping $B_{i}: C \rightarrow X$ be $\zeta_{i}$-strictly pseudocontractive and $\eta_{i}$-strongly accretive with $\zeta_{i}+\eta_{i} \geq 1$ for $i=1$, 2. Let $f \in \Xi_{C}$ with a contractive coefficient $\rho \in(0,1)$. Let $\left\{\lambda_{n}\right\}_{n=0}^{\infty}$ be a sequence of positive numbers in $(0, b]$ for some $b \in(0,1)$ and $\left\{T_{n}\right\}_{n=0}^{\infty}$ be an infinite family of nonexpansive self-mappings on $C$ such that $F:=\bigcap_{n=0}^{\infty} \operatorname{Fix}\left(T_{n}\right) \cap \Omega \neq \emptyset$, where $\Omega$ is the fixed point set of the mapping $G=\Pi_{C}\left(I-\mu_{1} B_{1}\right) \Pi_{C}\left(I-\mu_{2} B_{2}\right)$ with $1-\frac{\zeta_{i}}{1+\zeta_{i}}\left(1-\sqrt{\frac{1-\eta_{i}}{\zeta_{i}}}\right) \leq \mu_{i} \leq 1$ for $i=1,2$. For an arbitrary $x_{0} \in C$, let $\left\{x_{n}\right\}$ be generated by

$$
\left\{\begin{array}{l}
z_{n}=\sigma_{n} x_{n}+\left(1-\sigma_{n}\right) G x_{n}, \\
y_{n}=\alpha_{n} x_{n}+\left(1-\alpha_{n}\right) W_{n} z_{n}, \\
x_{n+1}=\beta_{n} f\left(x_{n}\right)+\left(1-\beta_{n}\right) y_{n}, \quad \forall n \geq 0,
\end{array}\right.
$$

where $W_{n}$ is the $W$-mapping generated by $T_{n}, T_{n-1}, \ldots, T_{0}$ and $\lambda_{n}, \lambda_{n-1}, \ldots, \lambda_{0}$, and $\left\{\alpha_{n}\right\}$, $\left\{\beta_{n}\right\}$ and $\left\{\sigma_{n}\right\}$ are sequences in $[0,1]$. Suppose that the following conditions hold:

(i) $0 \leq \beta_{n} \leq 1-\rho, \forall n \geq n_{0}$ for some $n_{0} \geq 0$, and $\sum_{n=0}^{\infty} \beta_{n}=\infty$;

(ii) $\lim _{n \rightarrow \infty}\left|\frac{\left.\beta_{n+1}\right)}{1-\left(1-\beta_{n+1}\right) \alpha_{n+1}}-\frac{\beta_{n}}{1-\left(1-\beta_{n}\right) \alpha_{n}}\right|=0$ and $\lim _{n \rightarrow \infty}\left|\sigma_{n+1}-\sigma_{n}\right|=0$;

(iii) $0<\liminf _{n \rightarrow \infty} \alpha_{n} \leq \lim \sup _{n \rightarrow \infty} \alpha_{n}<1$;

(iv) $0<\liminf _{n \rightarrow \infty} \sigma_{n} \leq \limsup _{n \rightarrow \infty} \sigma_{n}<1$.

Then

$$
x_{n} \rightarrow q \in F \quad \Longleftrightarrow \quad \beta_{n}\left(f\left(x_{n}\right)-x_{n}\right) \rightarrow 0 .
$$

In this case,

(i) if $X$ is uniformly smooth, then $q \in F$ solves the VIP

$$
\langle q-f(q), J(q-p)\rangle, \quad \forall p \in F
$$

(ii) if $X$ has a weakly continuous duality map $J_{\varphi}$ with gauge $\varphi$, then $q \in F$ solves the VIP

$$
\left\langle q-f(q), J_{\varphi}(q-p)\right\rangle \leq 0, \quad \forall p \in F
$$

Proof First of all, let us show that $\left\{x_{n}\right\}$ is bounded. Indeed, taking an element $p \in F=$ $\bigcap_{n=0}^{\infty} \operatorname{Fix}\left(T_{n}\right) \cap \Omega$ arbitrarily, we obtain that $G p=p$ and $p=W_{n} p$ for all $n \geq 0$. By 
Lemma 3.2, we know that $G$ is nonexpansive. It follows from the nonexpansivity of $G$ and $W_{n}$ that

$$
\begin{aligned}
\left\|z_{n}-p\right\| & \leq \sigma_{n}\left\|x_{n}-p\right\|+\left(1-\sigma_{n}\right)\left\|G x_{n}-p\right\| \leq\left\|x_{n}-p\right\|, \\
\left\|y_{n}-p\right\| & \leq \alpha_{n}\left\|x_{n}-p\right\|+\left(1-\alpha_{n}\right)\left\|W_{n} z_{n}-p\right\| \\
& \leq \alpha_{n}\left\|x_{n}-p\right\|+\left(1-\alpha_{n}\right)\left\|z_{n}-p\right\| \\
& \leq \alpha_{n}\left\|x_{n}-p\right\|+\left(1-\alpha_{n}\right)\left\|x_{n}-p\right\| \\
& =\left\|x_{n}-p\right\|
\end{aligned}
$$

and

$$
\begin{aligned}
\left\|x_{n+1}-p\right\| & \leq \beta_{n}\left\|f\left(x_{n}\right)-p\right\|+\left(1-\beta_{n}\right)\left\|y_{n}-p\right\| \\
& \leq \beta_{n}\left(\left\|f\left(x_{n}\right)-f(p)\right\|+\|f(p)-p\|\right)+\left(1-\beta_{n}\right)\left\|x_{n}-p\right\| \\
& \leq \beta_{n}\left(\rho\left\|x_{n}-p\right\|+\|f(p)-p\|\right)+\left(1-\beta_{n}\right)\left\|x_{n}-p\right\| \\
& =\left(1-(1-\rho) \beta_{n}\right)\left\|x_{n}-p\right\|+\beta_{n}\|f(p)-p\| \\
& \leq \max \left\{\left\|x_{n}-p\right\|, \frac{\|f(p)-p\|}{1-\rho}\right\} .
\end{aligned}
$$

By induction, we have

$$
\left\|x_{n}-p\right\| \leq \max \left\{\left\|x_{0}-p\right\|, \frac{\|f(p)-p\|}{1-\rho}\right\}, \quad \forall n \geq 0 .
$$

Hence $\left\{x_{n}\right\}$ is bounded, and so are the sequences $\left\{y_{n}\right\},\left\{z_{n}\right\},\left\{G x_{n}\right\},\left\{W_{n} z_{n}\right\}$ and $\left\{f\left(x_{n}\right)\right\}$.

Suppose that $x_{n} \rightarrow q \in F$ as $n \rightarrow \infty$. Then $q=G q$ and $q=W_{n} q$ for all $n \geq 0$. From (3.1) it follows that

$$
\begin{aligned}
\left\|z_{n}-q\right\| & \leq \sigma_{n}\left\|x_{n}-q\right\|+\left(1-\sigma_{n}\right)\left\|G x_{n}-q\right\| \\
& \leq \sigma_{n}\left\|x_{n}-q\right\|+\left(1-\sigma_{n}\right)\left\|x_{n}-q\right\| \\
& =\left\|x_{n}-q\right\|
\end{aligned}
$$

and

$$
\begin{aligned}
\left\|y_{n}-q\right\| & \leq \alpha_{n}\left\|x_{n}-q\right\|+\left(1-\alpha_{n}\right)\left\|W_{n} z_{n}-q\right\| \\
& \leq \alpha_{n}\left\|x_{n}-q\right\|+\left(1-\alpha_{n}\right)\left\|z_{n}-q\right\| \\
& \leq \alpha_{n}\left\|x_{n}-q\right\|+\left(1-\alpha_{n}\right)\left\|x_{n}-q\right\| \\
& =\left\|x_{n}-q\right\| \rightarrow 0 \quad(n \rightarrow \infty),
\end{aligned}
$$

that is, $x_{n} \rightarrow q$. Again from (3.1) we obtain that

$$
\begin{aligned}
\left\|\beta_{n}\left(f\left(x_{n}\right)-x_{n}\right)\right\| & =\left\|x_{n+1}-x_{n}-\left(1-\beta_{n}\right)\left(y_{n}-x_{n}\right)\right\| \\
& \leq\left\|x_{n+1}-x_{n}\right\|+\left(1-\beta_{n}\right)\left\|y_{n}-x_{n}\right\| \rightarrow 0 .
\end{aligned}
$$


Conversely, suppose that $\beta_{n}\left(f\left(x_{n}\right)-x_{n}\right) \rightarrow 0(n \rightarrow \infty)$. Put $\gamma_{n}=\left(1-\beta_{n}\right) \alpha_{n}$ for each $n \geq 0$. Then it follows from conditions (i) and (iii) that

$$
\alpha_{n} \geq \gamma_{n}=\left(1-\beta_{n}\right) \alpha_{n} \geq(1-(1-\rho)) \alpha_{n}=\rho \alpha_{n}, \quad \forall n \geq n_{0},
$$

and hence

$$
0<\liminf _{n \rightarrow \infty} \gamma_{n} \leq \limsup _{n \rightarrow \infty} \gamma_{n}<1
$$

Define $\hat{z}_{n}$ by

$$
x_{n+1}=\gamma_{n} x_{n}+\left(1-\gamma_{n}\right) \hat{z}_{n}, \quad \forall n \geq 0 \text {. }
$$

Observe that

$$
\begin{aligned}
& \hat{z}_{n+1}-\hat{z}_{n}=\frac{x_{n+2}-\gamma_{n+1} x_{n+1}}{1-\gamma_{n+1}}-\frac{x_{n+1}-\gamma_{n} x_{n}}{1-\gamma_{n}} \\
& =\frac{\beta_{n+1} f\left(x_{n+1}\right)+\left(1-\beta_{n+1}\right) y_{n+1}-\gamma_{n+1} x_{n+1}}{1-\gamma_{n+1}}-\frac{\beta_{n} f\left(x_{n}\right)+\left(1-\beta_{n}\right) y_{n}-\gamma_{n} x_{n}}{1-\gamma_{n}} \\
& =\left(\frac{\beta_{n+1} f\left(x_{n+1}\right)}{1-\gamma_{n+1}}-\frac{\beta_{n} f\left(x_{n}\right)}{1-\gamma_{n}}\right)-\frac{\left(1-\beta_{n}\right)\left[\alpha_{n} x_{n}+\left(1-\alpha_{n}\right) W_{n} z_{n}\right]-\gamma_{n} x_{n}}{1-\gamma_{n}} \\
& +\frac{\left(1-\beta_{n+1}\right)\left[\alpha_{n+1} x_{n+1}+\left(1-\alpha_{n+1}\right) W_{n+1} z_{n+1}\right]-\gamma_{n+1} x_{n+1}}{1-\gamma_{n+1}} \\
& =\left(\frac{\beta_{n+1} f\left(x_{n+1}\right)}{1-\gamma_{n+1}}-\frac{\beta_{n} f\left(x_{n}\right)}{1-\gamma_{n}}\right) \\
& +\frac{\left(1-\beta_{n+1}\right)\left(1-\alpha_{n+1}\right) W_{n+1} z_{n+1}}{1-\gamma_{n+1}}-\frac{\left(1-\beta_{n}\right)\left(1-\alpha_{n}\right) W_{n} z_{n}}{1-\gamma_{n}} \\
& =\left(\frac{\beta_{n+1} f\left(x_{n+1}\right)}{1-\gamma_{n+1}}-\frac{\beta_{n} f\left(x_{n}\right)}{1-\gamma_{n}}\right)+\left(W_{n+1} z_{n+1}-W_{n} z_{n}\right) \\
& -\frac{\beta_{n+1}}{1-\gamma_{n+1}} W_{n+1} z_{n+1}+\frac{\beta_{n}}{1-\gamma_{n}} W_{n} z_{n} \\
& =\left(\frac{\beta_{n+1}}{1-\gamma_{n+1}}-\frac{\beta_{n}}{1-\gamma_{n}}\right) f\left(x_{n+1}\right)+\frac{\beta_{n}}{1-\gamma_{n}}\left(f\left(x_{n+1}\right)-f\left(x_{n}\right)\right)+\left(W_{n+1} z_{n+1}-W_{n} z_{n}\right) \\
& -\left(\frac{\beta_{n+1}}{1-\gamma_{n+1}}-\frac{\beta_{n}}{1-\gamma_{n}}\right) W_{n+1} z_{n+1}-\left(W_{n+1} z_{n+1}-W_{n} z_{n}\right) \frac{\beta_{n}}{1-\gamma_{n}} \\
& =\left(\frac{\beta_{n+1}}{1-\gamma_{n+1}}-\frac{\beta_{n}}{1-\gamma_{n}}\right)\left(f\left(x_{n+1}\right)-W_{n+1} z_{n+1}\right)+\frac{\beta_{n}}{1-\gamma_{n}}\left(f\left(x_{n+1}\right)-f\left(x_{n}\right)\right) \\
& +\frac{1-\gamma_{n}-\beta_{n}}{1-\gamma_{n}}\left(W_{n+1} z_{n+1}-W_{n} z_{n}\right) \text {. }
\end{aligned}
$$

It follows that

$$
\begin{aligned}
\left\|\hat{z}_{n+1}-\hat{z}_{n}\right\| \leq & \left|\frac{\beta_{n+1}}{1-\gamma_{n+1}}-\frac{\beta_{n}}{1-\gamma_{n}}\right|\left\|f\left(x_{n+1}\right)-W_{n+1} z_{n+1}\right\|+\frac{\beta_{n}}{1-\gamma_{n}}\left\|f\left(x_{n+1}\right)-f\left(x_{n}\right)\right\| \\
& +\frac{1-\gamma_{n}-\beta_{n}}{1-\gamma_{n}}\left\|W_{n+1} z_{n+1}-W_{n} z_{n}\right\|
\end{aligned}
$$




$$
\begin{aligned}
\leq & \left|\frac{\beta_{n+1}}{1-\gamma_{n+1}}-\frac{\beta_{n}}{1-\gamma_{n}}\right|\left(\left\|f\left(x_{n+1}\right)\right\|+\left\|W_{n+1} z_{n+1}\right\|\right)+\frac{\rho \beta_{n}}{1-\gamma_{n}}\left\|x_{n+1}-x_{n}\right\| \\
& +\frac{1-\gamma_{n}-\beta_{n}}{1-\gamma_{n}}\left(\left\|W_{n+1} z_{n+1}-W_{n+1} z_{n}\right\|+\left\|W_{n+1} z_{n}-W_{n} z_{n}\right\|\right) \\
\leq & \left|\frac{\beta_{n+1}}{1-\gamma_{n+1}}-\frac{\beta_{n}}{1-\gamma_{n}}\right|\left(\left\|f\left(x_{n+1}\right)\right\|+\left\|W_{n+1} z_{n+1}\right\|\right)+\frac{\rho \beta_{n}}{1-\gamma_{n}}\left\|x_{n+1}-x_{n}\right\| \\
& +\frac{1-\gamma_{n}-\beta_{n}}{1-\gamma_{n}}\left(\left\|z_{n+1}-z_{n}\right\|+\left\|W_{n+1} z_{n}-W_{n} z_{n}\right\|\right) .
\end{aligned}
$$

In the meantime, simple calculations show that

$$
z_{n+1}-z_{n}=\sigma_{n+1}\left(x_{n+1}-x_{n}\right)+\left(1-\sigma_{n+1}\right)\left(G x_{n+1}-G x_{n}\right)+\left(\sigma_{n+1}-\sigma_{n}\right)\left(x_{n}-G x_{n}\right),
$$

which hence yields

$$
\begin{aligned}
\left\|z_{n+1}-z_{n}\right\| & \leq \sigma_{n+1}\left\|x_{n+1}-x_{n}\right\|+\left(1-\sigma_{n+1}\right)\left\|G x_{n+1}-G x_{n}\right\|+\left|\sigma_{n+1}-\sigma_{n}\right|\left\|x_{n}-G x_{n}\right\| \\
& \leq \sigma_{n+1}\left\|x_{n+1}-x_{n}\right\|+\left(1-\sigma_{n+1}\right)\left\|x_{n+1}-x_{n}\right\|+\left|\sigma_{n+1}-\sigma_{n}\right|\left\|x_{n}-G x_{n}\right\| \\
& =\left\|x_{n+1}-x_{n}\right\|+\left|\sigma_{n+1}-\sigma_{n}\right|\left\|x_{n}-G x_{n}\right\| .
\end{aligned}
$$

Taking into account the nonexpansivity of $T_{k}$ and $U_{n, k}$, from (CWY) we have

$$
\begin{aligned}
\left\|W_{n+1} z_{n}-W_{n} z_{n}\right\| & =\left\|\lambda_{0} T_{0} U_{n+1,1} z_{n}-\lambda_{0} T_{0} U_{n, 1} z_{n}\right\| \\
& \leq \lambda_{0}\left\|U_{n+1,1} z_{n}-U_{n, 1} z_{n}\right\| \\
& =\lambda_{0}\left\|\lambda_{1} T_{1} U_{n+1,2} z_{n}-\lambda_{1} T_{1} U_{n, 2} z_{n}\right\| \\
& \leq \lambda_{0} \lambda_{1}\left\|U_{n+1,2} z_{n}-U_{n, 2} z_{n}\right\| \\
& \leq \cdots \\
& \leq \lambda_{0} \lambda_{1} \cdots \lambda_{n}\left\|U_{n+1, n+1} z_{n}-U_{n, n+1} z_{n}\right\| \\
& =\lambda_{0} \lambda_{1} \cdots \lambda_{n+1}\left\|T_{n+1} z_{n}-z_{n}\right\| \\
& \leq M_{0} \prod_{k=0}^{n+1} \lambda_{k},
\end{aligned}
$$

where $\sup _{n \geq 0}\left\|T_{n+1} z_{n}-z_{n}\right\| \leq M_{0}$ for some $M_{0}>0$. Thus, from (3.4), (3.5) and (3.6), we get

$$
\begin{aligned}
& \left\|\hat{z}_{n+1}-\hat{z}_{n}\right\| \\
& \leq\left|\frac{\beta_{n+1}}{1-\gamma_{n+1}}-\frac{\beta_{n}}{1-\gamma_{n}}\right|\left(\left\|f\left(x_{n+1}\right)\right\|+\left\|W_{n+1} z_{n+1}\right\|\right)+\frac{\rho \beta_{n}}{1-\gamma_{n}}\left\|x_{n+1}-x_{n}\right\| \\
& \quad+\frac{1-\gamma_{n}-\beta_{n}}{1-\gamma_{n}}\left(\left\|x_{n+1}-x_{n}\right\|+\left|\sigma_{n+1}-\sigma_{n}\right|\left\|x_{n}-G x_{n}\right\|+M_{0} \prod_{k=0}^{n+1} \lambda_{k}\right) \\
& \leq\left\|x_{n+1}-x_{n}\right\|+\left|\frac{\beta_{n+1}}{1-\gamma_{n+1}}-\frac{\beta_{n}}{1-\gamma_{n}}\right|\left(\left\|f\left(x_{n+1}\right)\right\|+\left\|W_{n+1} z_{n+1}\right\|\right)
\end{aligned}
$$




$$
\begin{aligned}
& +\left|\sigma_{n+1}-\sigma_{n}\right||| x_{n}-G x_{n} \|+M_{0} \prod_{k=0}^{n+1} \lambda_{k} \\
\leq & \left\|x_{n+1}-x_{n}\right\|+M\left(\left|\frac{\beta_{n+1}}{1-\gamma_{n+1}}-\frac{\beta_{n}}{1-\gamma_{n}}\right|+\left|\sigma_{n+1}-\sigma_{n}\right|+\prod_{k=0}^{n+1} \lambda_{k}\right),
\end{aligned}
$$

where $\sup _{n \geq 0}\left\{\left\|f\left(x_{n}\right)\right\|+\left\|W_{n} z_{n}\right\|+\left\|G x_{n}\right\|+\left\|x_{n}\right\|+M_{0}\right\} \leq M$ for some $M>0$. Then it immediately follows that

$$
\left\|\hat{z}_{n+1}-\hat{z}_{n}\right\|-\left\|x_{n+1}-x_{n}\right\| \leq M\left(\left|\frac{\beta_{n+1}}{1-\gamma_{n+1}}-\frac{\beta_{n}}{1-\gamma_{n}}\right|+\left|\sigma_{n+1}-\sigma_{n}\right|+\prod_{k=0}^{n+1} \lambda_{k}\right) .
$$

From condition (ii) and $0<\lambda_{k} \leq b<1, \forall k \geq 0$, we deduce that

$$
\limsup _{n \rightarrow \infty}\left(\left\|\hat{z}_{n+1}-\hat{z}_{n}\right\|-\left\|x_{n+1}-x_{n}\right\|\right) \leq 0 .
$$

Hence by Lemma 2.12 we have

$$
\lim _{n \rightarrow \infty}\left\|\hat{z}_{n}-x_{n}\right\|=0
$$

It follows from (3.2) and (3.3) that

$$
\lim _{n \rightarrow \infty}\left\|x_{n+1}-x_{n}\right\|=\lim _{n \rightarrow \infty}\left(1-\gamma_{n}\right)\left\|\hat{z}_{n}-x_{n}\right\|=0
$$

From (3.1) we have

$$
x_{n+1}-x_{n}=\beta_{n}\left(f\left(x_{n}\right)-x_{n}\right)+\left(1-\beta_{n}\right)\left(y_{n}-x_{n}\right) .
$$

This implies that

$$
\begin{aligned}
\rho\left\|y_{n}-x_{n}\right\| & \leq\left(1-\beta_{n}\right)\left\|y_{n}-x_{n}\right\| \\
& =\left\|x_{n+1}-x_{n}-\beta_{n}\left(f\left(x_{n}\right)-x_{n}\right)\right\| \\
& \leq\left\|x_{n+1}-x_{n}\right\|+\left\|\beta_{n}\left(f\left(x_{n}\right)-x_{n}\right)\right\| .
\end{aligned}
$$

Since $x_{n+1}-x_{n} \rightarrow 0$ and $\beta_{n}\left(f\left(x_{n}\right)-x_{n}\right) \rightarrow 0$, we get

$$
\lim _{n \rightarrow \infty}\left\|y_{n}-x_{n}\right\|=0
$$

Observe that

$$
y_{n}-x_{n}=\left(1-\alpha_{n}\right)\left(W_{n} z_{n}-x_{n}\right) .
$$

It follows from condition (iii), (3.7) and (3.8) that

$$
\lim _{n \rightarrow \infty}\left\|x_{n}-W_{n} z_{n}\right\|=0 .
$$


Also, utilizing Lemma 2.13, we obtain from (3.1) that for $p \in F$

$$
\begin{aligned}
\left\|z_{n}-p\right\|^{2} & =\left\|\sigma_{n}\left(x_{n}-p\right)+\left(1-\sigma_{n}\right)\left(G x_{n}-p\right)\right\|^{2} \\
& \leq \sigma_{n}\left\|x_{n}-p\right\|^{2}+\left(1-\sigma_{n}\right)\left\|G x_{n}-p\right\|^{2}-\sigma_{n}\left(1-\sigma_{n}\right) g\left(\left\|x_{n}-G x_{n}\right\|\right) \\
& \leq \sigma_{n}\left\|x_{n}-p\right\|^{2}+\left(1-\sigma_{n}\right)\left\|x_{n}-p\right\|^{2}-\sigma_{n}\left(1-\sigma_{n}\right) g\left(\left\|x_{n}-G x_{n}\right\|\right) \\
& =\left\|x_{n}-p\right\|^{2}-\sigma_{n}\left(1-\sigma_{n}\right) g\left(\left\|x_{n}-G x_{n}\right\|\right),
\end{aligned}
$$

and hence

$$
\begin{aligned}
\left\|y_{n}-p\right\|^{2} & \leq \alpha_{n}\left\|x_{n}-p\right\|^{2}+\left(1-\alpha_{n}\right)\left\|W_{n} z_{n}-p\right\|^{2} \\
& \leq \alpha_{n}\left\|x_{n}-p\right\|^{2}+\left(1-\alpha_{n}\right)\left\|z_{n}-p\right\|^{2} \\
& \leq \alpha_{n}\left\|x_{n}-p\right\|^{2}+\left(1-\alpha_{n}\right)\left[\left\|x_{n}-p\right\|^{2}-\sigma_{n}\left(1-\sigma_{n}\right) g\left(\left\|x_{n}-G x_{n}\right\|\right)\right] \\
& =\left\|x_{n}-p\right\|^{2}-\left(1-\alpha_{n}\right) \sigma_{n}\left(1-\sigma_{n}\right) g\left(\left\|x_{n}-G x_{n}\right\|\right) .
\end{aligned}
$$

Thus, we get

$$
\begin{aligned}
\left(1-\alpha_{n}\right) \sigma_{n}\left(1-\sigma_{n}\right) g\left(\left\|x_{n}-G x_{n}\right\|\right) & \leq\left\|x_{n}-p\right\|^{2}-\left\|y_{n}-p\right\|^{2} \\
& \leq\left(\left\|x_{n}-p\right\|+\left\|y_{n}-p\right\|\right)\left\|x_{n}-y_{n}\right\| .
\end{aligned}
$$

From (3.7), conditions (iii), (iv) and the boundedness of $\left\{x_{n}\right\}$ and $\left\{y_{n}\right\}$, it follows that

$$
\lim _{n \rightarrow \infty} g\left(\left\|x_{n}-G x_{n}\right\|\right)=0
$$

Utilizing the properties of $g$, we have

$$
\lim _{n \rightarrow \infty}\left\|x_{n}-G x_{n}\right\|=0
$$

This immediately implies that

$$
\lim _{n \rightarrow \infty}\left\|z_{n}-x_{n}\right\|=\lim _{n \rightarrow \infty}\left(1-\sigma_{n}\right)\left\|G x_{n}-x_{n}\right\|=0 .
$$

Note that

$$
\left\|x_{n}-W_{n} x_{n}\right\| \leq\left\|x_{n}-W_{n} z_{n}\right\|+\left\|W_{n} z_{n}-W_{n} x_{n}\right\| \leq\left\|x_{n}-W_{n} z_{n}\right\|+\left\|z_{n}-x_{n}\right\|,
$$

which together with (3.9) and (3.11) implies that

$$
\lim _{n \rightarrow \infty}\left\|x_{n}-W_{n} x_{n}\right\|=0
$$

Also, note that

$$
\left\|W x_{n}-x_{n}\right\| \leq\left\|W x_{n}-W_{n} x_{n}\right\|+\left\|W_{n} x_{n}-x_{n}\right\| .
$$


From [52, Remark 2.2] (see also [53, Remark 3.1]), we have

$$
\lim _{n \rightarrow \infty}\left\|W x_{n}-W_{n} x_{n}\right\|=0
$$

It follows that

$$
\lim _{n \rightarrow \infty}\left\|W x_{n}-x_{n}\right\|=0
$$

In terms of (2.3) and Lemma 2.11, $W: C \rightarrow C$ is a nonexpansive mapping such that $\operatorname{Fix}(W)=\bigcap_{n=0}^{\infty} \operatorname{Fix}\left(T_{n}\right)$. Define a mapping $V x=(1-\theta) W x+\theta G x$, where $\theta$ is a constant in $(0,1)$. Then by Lemma 2.8, we have that $\operatorname{Fix}(V)=\operatorname{Fix}(W) \cap \operatorname{Fix}(G)=F$. Moreover, from (3.10) and (3.12), we get

$$
\left\|V x_{n}-x_{n}\right\| \leq(1-\theta)\left\|W x_{n}-x_{n}\right\|+\theta\left\|G x_{n}-x_{n}\right\| \rightarrow 0
$$

that is,

$$
\lim _{n \rightarrow \infty}\left\|V x_{n}-x_{n}\right\|=0
$$

In the following, we discuss two cases.

(i) Firstly, suppose that $X$ is uniformly smooth. Let $x_{t}$ be the unique fixed point of the contraction mapping $T_{t}$ given by

$$
T_{t} x=t f(x)(1-t) V x, \quad \forall t \in(0,1) .
$$

By Lemma 2.5, we can define $q:=s-\lim _{t \rightarrow 0^{+}} x_{t}$, and $q \in \operatorname{Fix}(V)=F$ solves the VIP

$$
\langle q-f(q), J(q-p)\rangle, \quad \forall p \in F .
$$

Let us show that

$$
\limsup _{n \rightarrow \infty}\left\langle f(q)-q, J\left(x_{n}-q\right)\right\rangle \leq 0 .
$$

Note that

$$
x_{t}-x_{n}=t\left(f\left(x_{t}\right)-x_{n}\right)+(1-t)\left(V x_{t}-x_{n}\right) \text {. }
$$

Applying Lemma 2.2, we derive

$$
\begin{aligned}
\| x_{t} & -x_{n} \|^{2} \\
& \leq(1-t)^{2}\left\|V x_{t}-x_{n}\right\|^{2}+2 t\left\langle f\left(x_{t}\right)-x_{n}, J\left(x_{t}-x_{n}\right)\right\rangle \\
& \leq(1-t)^{2}\left(\left\|V x_{t}-V x_{n}\right\|+\left\|V x_{n}-x_{n}\right\|\right)^{2}+2 t\left\langle f\left(x_{t}\right)-x_{t}, J\left(x_{t}-x_{n}\right)\right\rangle+2 t\left\|x_{t}-x_{n}\right\|^{2} \\
& \leq(1-t)^{2}\left\|x_{t}-x_{n}\right\|^{2}+a_{n}(t)+2 t\left\langle f\left(x_{t}\right)-x_{t}, J\left(x_{t}-x_{n}\right)\right\rangle+2 t\left\|x_{t}-x_{n}\right\|^{2},
\end{aligned}
$$


where

$$
a_{n}(t)=\left\|V x_{n}-x_{n}\right\|\left(2\left\|x_{t}-x_{n}\right\|+\left\|V x_{n}-x_{n}\right\|\right) \rightarrow 0 \quad \text { (due to (3.13)). }
$$

The last inequality implies

$$
\left\langle x_{t}-f\left(x_{t}\right), J\left(x_{t}-x_{n}\right)\right\rangle \leq \frac{t}{2}\left\|x_{t}-x_{n}\right\|^{2}+\frac{1}{2 t} a_{n}(t) .
$$

It follows that

$$
\limsup _{n \rightarrow \infty}\left\langle x_{t}-f\left(x_{t}\right), J\left(x_{t}-x_{n}\right)\right\rangle \leq M_{1} \frac{t}{2}
$$

where $M_{1}>0$ is a constant such that $M_{1} \geq\left\|x_{t}-x_{n}\right\|^{2}$ for all $n \geq 0$ and small enough $t \in(0,1)$. Taking the limsup as $t \rightarrow 0^{+}$in (3.15) and noticing the fact that the two limits are interchangeable due to the fact that the duality map $J$ is uniformly norm-to-norm continuous on any bounded subset of $X$, we get (3.14).

Now, let us show that $x_{n} \rightarrow q$ as $n \rightarrow \infty$.

Indeed, utilizing Lemma 2.2, we obtain from (3.1) that

$$
\begin{aligned}
\left\|z_{n}-q\right\|^{2} & \leq \sigma_{n}\left\|x_{n}-q\right\|^{2}+\left(1-\sigma_{n}\right)\left\|G x_{n}-q\right\|^{2} \leq\left\|x_{n}-q\right\|^{2}, \\
\left\|y_{n}-q\right\|^{2} & \leq \alpha_{n}\left\|x_{n}-q\right\|^{2}+\left(1-\alpha_{n}\right)\left\|W_{n} z_{n}-q\right\|^{2} \\
& \leq \alpha_{n}\left\|x_{n}-q\right\|^{2}+\left(1-\alpha_{n}\right)\left\|z_{n}-q\right\|^{2} \\
& \leq \alpha_{n}\left\|x_{n}-q\right\|^{2}+\left(1-\alpha_{n}\right)\left\|x_{n}-q\right\|^{2} \\
& =\left\|x_{n}-q\right\|^{2}
\end{aligned}
$$

and hence

$$
\begin{aligned}
\left\|x_{n+1}-q\right\|^{2} & =\left\|\beta_{n}\left(f\left(x_{n}\right)-f(q)\right)+\left(1-\beta_{n}\right)\left(y_{n}-q\right)+\beta_{n}(f(q)-q)\right\|^{2} \\
& \leq\left\|\beta_{n}\left(f\left(x_{n}\right)-f(q)\right)+\left(1-\beta_{n}\right)\left(y_{n}-q\right)\right\|^{2}+2 \beta_{n}\left\langle f(q)-q, J\left(x_{n+1}-q\right)\right\rangle \\
& \leq \beta_{n}\left\|f\left(x_{n}\right)-f(q)\right\|^{2}+\left(1-\beta_{n}\right)\left\|y_{n}-q\right\|^{2}+2 \beta_{n}\left\langle f(q)-q, J\left(x_{n+1}-q\right)\right\rangle \\
& \leq \beta_{n} \rho\left\|x_{n}-q\right\|^{2}+\left(1-\beta_{n}\right)\left\|x_{n}-q\right\|^{2}+2 \beta_{n}\left\langle f(q)-q, J\left(x_{n+1}-q\right)\right\rangle \\
& =\left(1-(1-\rho) \beta_{n}\right)\left\|x_{n}-q\right\|^{2}+2 \beta_{n}\left\langle f(q)-q, J\left(x_{n+1}-q\right)\right\rangle \\
& =\left(1-(1-\rho) \beta_{n}\right)\left\|x_{n}-q\right\|^{2}+(1-\rho) \beta_{n} \frac{2\left\langle f(q)-q, J\left(x_{n+1}-q\right)\right\rangle}{1-\rho} .
\end{aligned}
$$

Therefore, applying Lemma 2.1 to (3.17), we conclude from (3.14) and condition (i) that $x_{n} \rightarrow q$ as $n \rightarrow \infty$.

(ii) Secondly, suppose that $X$ has a weakly continuous duality map $J_{\varphi}$ with gauge $\varphi$. Let $x_{t}$ be the unique fixed point of the contraction mapping $T_{t}$ given by

$$
T_{t} x=t f(x)+(1-t) V x, \quad \forall t \in(0,1) .
$$


By Lemma 2.7, we can define $q:=s-\lim _{t \rightarrow 0^{+}} x_{t}$, and $q \in \operatorname{Fix}(V)=F$ solves the VIP

$$
\left\langle q-f(q), J_{\varphi}(q-p)\right\rangle \leq 0, \quad \forall p \in F
$$

Let us show that

$$
\limsup _{n \rightarrow \infty}\left\langle f(q)-q, J_{\varphi}\left(x_{n}-q\right)\right\rangle \leq 0
$$

We take a subsequence $\left\{x_{n_{k}}\right\}$ of $\left\{x_{n}\right\}$ such that

$$
\limsup _{n \rightarrow \infty}\left\langle f(q)-q, J_{\varphi}\left(x_{n}-q\right)\right\rangle=\lim _{k \rightarrow \infty}\left\langle f(q)-q, J_{\varphi}\left(x_{n_{k}}-q\right)\right\rangle
$$

Since $X$ is reflexive and $\left\{x_{n}\right\}$ is bounded, we may further assume that $x_{n_{k}} \rightarrow \bar{x}$ for some $\bar{x} \in C$. Since $J_{\varphi}$ is weakly continuous, utilizing Lemma $2.6(\mathrm{ii})$, we have

$$
\limsup _{k \rightarrow \infty} \Phi\left(\left\|x_{n_{k}}-x\right\|\right)=\limsup _{k \rightarrow \infty} \Phi\left(\left\|x_{n_{k}}-\bar{x}\right\|\right)+\Phi(\|x-\bar{x}\|), \quad \forall x \in X
$$

Put $\Gamma(x)=\limsup \sup _{k \rightarrow \infty} \Phi\left(\left\|x_{n_{k}}-x\right\|\right), \forall x \in X$. It follows that

$$
\Gamma(x)=\Gamma(\bar{x})+\Phi(\|x-\bar{x}\|), \quad \forall x \in X
$$

From (3.13), we have

$$
\begin{aligned}
\Gamma(V \bar{x}) & =\limsup _{k \rightarrow \infty} \Phi\left(\left\|x_{n_{k}}-V \bar{x}\right\|\right) \\
& =\limsup _{k \rightarrow \infty} \Phi\left(\left\|V x_{n_{k}}-V \bar{x}\right\|\right) \\
& \leq \limsup _{k \rightarrow \infty} \Phi\left(\left\|x_{n_{k}}-\bar{x}\right\|\right)=\Gamma(\bar{x}) .
\end{aligned}
$$

Furthermore, observe that

$$
\Gamma(V \bar{x})=\Gamma(\bar{x})+\Phi(\|V \bar{x}-\bar{x}\|)
$$

Combining (3.21) with (3.22), we obtain

$$
\Phi(\|V \bar{x}-\bar{x}\|) \leq 0
$$

Hence $V \bar{x}=\bar{x}$ and $\bar{x} \in \operatorname{Fix}(V)=F$. Thus, from (3.18) and (3.20), it is easy to see that

$$
\limsup _{n \rightarrow \infty}\left\langle f(q)-q, J_{\varphi}\left(x_{n}-q\right)\right\rangle=\left\langle f(q)-q, J_{\varphi}(\bar{x}-q)\right\rangle \leq 0
$$

Therefore, we deduce that (3.19) holds. 
Next, let us show that $x_{n} \rightarrow q$ as $n \rightarrow \infty$. Indeed, utilizing Lemma 2.6(i), we obtain from (3.1) that

$$
\begin{aligned}
\left\|z_{n}-q\right\| & \leq \sigma_{n}\left\|x_{n}-q\right\|+\left(1-\sigma_{n}\right)\left\|G x_{n}-q\right\| \leq\left\|x_{n}-q\right\|, \\
\left\|y_{n}-q\right\| & \leq \alpha_{n}\left\|x_{n}-q\right\|+\left(1-\alpha_{n}\right)\left\|W_{n} z_{n}-q\right\| \\
& \leq \alpha_{n}\left\|x_{n}-q\right\|+\left(1-\alpha_{n}\right)\left\|z_{n}-q\right\| \\
& \leq\left\|x_{n}-q\right\|,
\end{aligned}
$$

and hence

$$
\begin{aligned}
\Phi & \left(\left\|x_{n+1}-q\right\|\right) \\
& =\Phi\left(\left\|\beta_{n}\left(f\left(x_{n}\right)-q\right)+\left(1-\beta_{n}\right)\left(y_{n}-q\right)\right\|\right) \\
& =\Phi\left(\left\|\beta_{n}\left(f\left(x_{n}\right)-f(q)\right)+\left(1-\beta_{n}\right)\left(y_{n}-q\right)+\beta_{n}(f(q)-q)\right\|\right) \\
& \leq \Phi\left(\left\|\beta_{n}\left(f\left(x_{n}\right)-f(q)\right)+\left(1-\beta_{n}\right)\left(y_{n}-q\right)\right\|\right)+\beta_{n}\left\langle f(q)-q, J_{\varphi}\left(x_{n+1}-q\right)\right\rangle \\
& \leq \Phi\left(\beta_{n}\left\|f\left(x_{n}\right)-f(q)\right\|+\left(1-\beta_{n}\right)\left\|y_{n}-q\right\|\right)+\beta_{n}\left\langle f(q)-q, J_{\varphi}\left(x_{n+1}-q\right)\right\rangle \\
& \leq \Phi\left(\beta_{n} \rho\left\|x_{n}-q\right\|+\left(1-\beta_{n}\right)\left\|x_{n}-q\right\|\right)+\beta_{n}\left\langle f(q)-q, J_{\varphi}\left(x_{n+1}-q\right)\right\rangle \\
& \leq\left(1-(1-\rho) \beta_{n}\right) \Phi\left(\left\|x_{n}-q\right\|\right)+\beta_{n}\left\langle f(q)-q, J_{\varphi}\left(x_{n+1}-q\right)\right\rangle \\
& =\left(1-(1-\rho) \beta_{n}\right) \Phi\left(\left\|x_{n}-q\right\|\right)+(1-\rho) \beta_{n} \frac{\left\langle f(q)-q, J_{\varphi}\left(x_{n+1}-q\right)\right\rangle}{1-\rho} .
\end{aligned}
$$

Applying Lemma 2.1 to (3.23), we conclude from (3.19) and condition (i) that

$$
\Phi\left(\left\|x_{n}-q\right\|\right) \rightarrow 0 \quad(n \rightarrow \infty)
$$

which implies that $\left\|x_{n}-q\right\| \rightarrow 0(n \rightarrow \infty)$, i.e., $x_{n} \rightarrow q(n \rightarrow \infty)$. This completes the proof.

Corollary 3.1 The conclusion in Theorem 3.1 still holds, provided the conditions (i)-(iv) are replaced by the following:

(i) $0 \leq \beta_{n} \leq 1-\rho, \forall n \geq n_{0}$ for some $n_{0} \geq 0$;

(ii) $\lim _{n \rightarrow \infty}\left|\beta_{n}-\beta_{n+1}\right|=0$ and $\sum_{n=0}^{\infty} \beta_{n}=\infty$;

(iii) $\lim _{n \rightarrow \infty}\left|\alpha_{n}-\alpha_{n+1}\right|=0$ and $0<\liminf _{n \rightarrow \infty} \alpha_{n} \leq \lim \sup _{n \rightarrow \infty} \alpha_{n}<1$;

(iv) $\lim _{n \rightarrow \infty}\left|\sigma_{n}-\sigma_{n+1}\right|=0$ and $0<\liminf _{n \rightarrow \infty} \sigma_{n} \leq \lim \sup _{n \rightarrow \infty} \sigma_{n}<1$.

Proof Observe that

$$
\begin{aligned}
& \frac{\beta_{n+1}}{1-\left(1-\beta_{n+1}\right) \alpha_{n+1}}-\frac{\beta_{n}}{1-\left(1-\beta_{n}\right) \alpha_{n}} \\
& =\frac{\left(\beta_{n+1}-\beta_{n}\right)-\beta_{n+1} \alpha_{n}+\beta_{n} \alpha_{n+1}+\beta_{n+1} \beta_{n} \alpha_{n}-\beta_{n} \beta_{n+1} \alpha_{n+1}}{\left(1-\left(1-\beta_{n+1}\right) \alpha_{n+1}\right)\left(1-\left(1-\beta_{n}\right) \alpha_{n}\right)} \\
& =\frac{\left(\beta_{n+1}-\beta_{n}\right)-\beta_{n+1}\left(\alpha_{n}-\alpha_{n+1}\right)-\alpha_{n+1}\left(\beta_{n+1}-\beta_{n}\right)+\beta_{n} \beta_{n+1}\left(\alpha_{n}-\alpha_{n+1}\right)}{\left(1-\left(1-\beta_{n+1}\right) \alpha_{n+1}\right)\left(1-\left(1-\beta_{n}\right) \alpha_{n}\right)} \\
& =\frac{\left(\beta_{n+1}-\beta_{n}\right)\left(1-\alpha_{n+1}\right)-\beta_{n+1}\left(\alpha_{n}-\alpha_{n+1}\right)\left(1-\beta_{n}\right)}{\left(1-\left(1-\beta_{n+1}\right) \alpha_{n+1}\right)\left(1-\left(1-\beta_{n}\right) \alpha_{n}\right)} \text {. }
\end{aligned}
$$


Since $\lim _{n \rightarrow \infty}\left|\beta_{n}-\beta_{n+1}\right|=0$ and $\lim _{n \rightarrow \infty}\left|\alpha_{n}-\alpha_{n+1}\right|=0$, it follows that

$$
\lim _{n \rightarrow \infty}\left|\frac{\beta_{n+1}}{1-\left(1-\beta_{n+1}\right) \alpha_{n+1}}-\frac{\beta_{n}}{1-\left(1-\beta_{n}\right) \alpha_{n}}\right|=0 .
$$

Consequently, all the conditions of Theorem 3.1 are satisfied. So, utilizing Theorem 3.1, we obtain the desired result.

Corollary 3.2 Let $C$ be a nonempty closed convex subset of a uniformly convex Banach space X. Assume, in addition, that $X$ either is uniformly smooth or has a weakly continuous duality map $J_{\varphi}$ with gauge $\varphi$. Let $\Pi_{C}$ be a sunny nonexpansive retraction from $X$ onto $C$. Let the mapping $B_{i}: C \rightarrow X$ be $\zeta_{i}$-strictly pseudocontractive and $\eta_{i}$-strongly accretive with $\zeta_{i}+\eta_{i} \geq 1$ for $i=1,2$. Let $f \in \Xi_{C}$ with a contractive coefficient $\rho \in(0,1)$. Let $\left\{\lambda_{n}\right\}_{n=0}^{\infty}$ be a sequence of positive numbers in $(0, b]$ for some $b \in(0,1)$ and $\left\{T_{n}\right\}_{n=0}^{\infty}$ be an infinite family of nonexpansive self-mappings on $C$ such that $F:=\bigcap_{n=0}^{\infty} \operatorname{Fix}\left(T_{n}\right) \cap \Omega \neq \emptyset$, where $\Omega$ is the fixed point set of the mapping $G=\Pi_{C}\left(I-\mu_{1} B_{1}\right) \Pi_{C}\left(I-\mu_{2} B_{2}\right)$ with $1-\frac{\zeta_{i}}{1+\zeta_{i}}\left(1-\sqrt{\frac{1-\eta_{i}}{\zeta_{i}}}\right) \leq \mu_{i} \leq 1$ for $i=1,2$. Suppose that $\left\{\alpha_{n}\right\},\left\{\beta_{n}\right\}$ and $\left\{\sigma_{n}\right\}$ are sequences in $[0,1]$ satisfying the following conditions:

(i) $\lim _{n \rightarrow \infty} \beta_{n}=0$ and $\sum_{n=0}^{\infty} \beta_{n}=\infty$;

(ii) $\lim _{n \rightarrow \infty}\left|\sigma_{n+1}-\sigma_{n}\right|=0$;

(iii) $0<\liminf _{n \rightarrow \infty} \alpha_{n} \leq \limsup _{n \rightarrow \infty} \alpha_{n}<1$;

(iv) $0<\liminf _{n \rightarrow \infty} \sigma_{n} \leq \limsup _{n \rightarrow \infty} \sigma_{n}<1$.

Then, for an arbitrary but fixed $x_{0} \in C$, the sequence $\left\{x_{n}\right\}$ defined by (3.1) converges strongly to some $q \in F$. Moreover,

(i) if $X$ is uniformly smooth, then $q \in F$ solves the VIP

$$
\langle q-f(q), J(q-p)\rangle, \quad \forall p \in F
$$

(ii) if $X$ has a weakly continuous duality map $J_{\varphi}$ with gauge $\varphi$, then $q \in F$ solves the VIP

$$
\left\langle q-f(q), J_{\varphi}(q-p)\right\rangle \leq 0, \quad \forall p \in F
$$

Proof Repeating the same arguments as those in the proof of Theorem 3.1, we know that $\left\{x_{n}\right\}$ is bounded, and so are the sequences $\left\{y_{n}\right\},\left\{z_{n}\right\},\left\{G x_{n}\right\},\left\{W_{n} z_{n}\right\}$ and $\left\{f\left(x_{n}\right)\right\}$. Since $\lim _{n \rightarrow \infty} \beta_{n}=0$, it is easy to see that the following hold:

(i) $\beta_{n}\left(f\left(x_{n}\right)-x_{n}\right) \rightarrow 0(n \rightarrow \infty)$;

(ii) $0 \leq \beta_{n} \leq 1-\rho, \forall n \geq n_{0}$ for some integer $n_{0} \geq 0$;

(iii) $\lim _{n \rightarrow \infty}\left|\frac{\left.\beta_{n+1}\right) \alpha_{n+1}}{1-\left(1-\beta_{n+1}\right) \alpha_{n+1}}-\frac{\beta_{n}}{1-\left(1-\beta_{n}\right) \alpha_{n}}\right|=0$.

Therefore, all the conditions of Theorem 3.1 are satisfied. So, utilizing Theorem 3.1, we derive the desired result.

To end this paper, we give a weak convergence theorem for three-step Mann iterations (3.1) involving GSVI (1.2) and an infinite family of nonexpansive mappings $T_{0}, T_{1}, \ldots$ in a Hilbert space $H$.

Theorem 3.2 Let $C$ be a nonempty closed convex subset of a Hilbert space $H$. Let the mapping $B_{i}: C \rightarrow H$ be $\beta_{i}$-inverse strongly monotone for $i=1,2$. Let $f \in \Xi_{C}$ with a contractive coefficient $\rho \in(0,1)$. Let $\left\{\lambda_{n}\right\}_{n=0}^{\infty}$ be a sequence of positive numbers in $(0, b]$ for 
some $b \in(0,1)$, and let $\left\{T_{n}\right\}_{n=0}^{\infty}$ be an infinite family of nonexpansive self-mappings on $C$ such that $F:=\bigcap_{n=0}^{\infty} \operatorname{Fix}\left(T_{n}\right) \cap \Omega \neq \emptyset$, where $\Omega$ is the fixed point set of the mapping $G=P_{C}\left(I-\mu_{1} B_{1}\right) P_{C}\left(I-\mu_{2} B_{2}\right)$ with $0<\mu_{i} \leq 2 \beta_{i}$ for $i=1,2$. Suppose that $\left\{\alpha_{n}\right\},\left\{\beta_{n}\right\}$ and $\left\{\sigma_{n}\right\}$ are sequences in $[0,1]$ satisfying the following conditions:

(i) $\sum_{n=0}^{\infty} \beta_{n}<\infty$;

(ii) $0<\liminf _{n \rightarrow \infty} \alpha_{n} \leq \limsup _{n \rightarrow \infty} \alpha_{n}<1$;

(iii) $0<\liminf _{n \rightarrow \infty} \sigma_{n} \leq \limsup _{n \rightarrow \infty} \sigma_{n}<1$.

Then, for an arbitrary but fixed $x_{0} \in C$, the sequence $\left\{x_{n}\right\}$ defined by (3.1) converges weakly to a point in $F$.

Proof First of all, by Lemma 1.1, we know that $G: C \rightarrow C$ is nonexpansive. Take an arbitrary $p \in F$. Repeating the same arguments as those in the proof of Theorem 3.1, we know that $\left\{x_{n}\right\}$ is bounded, and so are the sequences $\left\{y_{n}\right\},\left\{z_{n}\right\},\left\{G x_{n}\right\},\left\{W_{n} z_{n}\right\}$ and $\left\{f\left(x_{n}\right)\right\}$.

It follows from (2.2) and (3.1) that

$$
\begin{aligned}
\left\|z_{n}-p\right\|^{2}= & \sigma_{n}\left\|x_{n}-p\right\|^{2}+\left(1-\sigma_{n}\right)\left\|G x_{n}-p\right\|^{2}-\sigma_{n}\left(1-\sigma_{n}\right)\left\|x_{n}-G x_{n}\right\|^{2} \\
\leq & \sigma_{n}\left\|x_{n}-p\right\|^{2}+\left(1-\sigma_{n}\right)\left\|x_{n}-p\right\|^{2}-\sigma_{n}\left(1-\sigma_{n}\right)\left\|x_{n}-G x_{n}\right\|^{2} \\
= & \left\|x_{n}-p\right\|^{2}-\sigma_{n}\left(1-\sigma_{n}\right)\left\|x_{n}-G x_{n}\right\|^{2}, \\
\left\|y_{n}-p\right\|^{2}= & \alpha_{n}\left\|x_{n}-p\right\|^{2}+\left(1-\alpha_{n}\right)\left\|W_{n} z_{n}-p\right\|^{2}-\alpha_{n}\left(1-\alpha_{n}\right)\left\|x_{n}-W_{n} z_{n}\right\|^{2} \\
\leq & \alpha_{n}\left\|x_{n}-p\right\|^{2}+\left(1-\alpha_{n}\right)\left\|z_{n}-p\right\|^{2}-\alpha_{n}\left(1-\alpha_{n}\right)\left\|x_{n}-W_{n} z_{n}\right\|^{2} \\
\leq & \alpha_{n}\left\|x_{n}-p\right\|^{2}+\left(1-\alpha_{n}\right)\left[\left\|x_{n}-p\right\|^{2}-\sigma_{n}\left(1-\sigma_{n}\right)\left\|x_{n}-G x_{n}\right\|^{2}\right] \\
& -\alpha_{n}\left(1-\alpha_{n}\right)\left\|x_{n}-W_{n} z_{n}\right\|^{2} \\
= & \left\|x_{n}-p\right\|^{2}-\left(1-\alpha_{n}\right) \sigma_{n}\left(1-\sigma_{n}\right)\left\|x_{n}-G x_{n}\right\|^{2}-\alpha_{n}\left(1-\alpha_{n}\right)\left\|x_{n}-W_{n} z_{n}\right\|^{2},
\end{aligned}
$$

and hence

$$
\begin{aligned}
\left\|x_{n+1}-p\right\|^{2} \leq & \left(1-\beta_{n}\right)\left\|y_{n}-p\right\|^{2}+\beta_{n}\left\|f\left(x_{n}\right)-p\right\|^{2} \\
\leq & \left\|y_{n}-p\right\|^{2}+\beta_{n}\left\|f\left(x_{n}\right)-p\right\|^{2} \\
\leq & \left\|x_{n}-p\right\|^{2}-\left(1-\alpha_{n}\right) \sigma_{n}\left(1-\sigma_{n}\right)\left\|x_{n}-G x_{n}\right\|^{2} \\
& \quad-\alpha_{n}\left(1-\alpha_{n}\right)\left\|x_{n}-W_{n} z_{n}\right\|^{2}+\beta_{n}\left\|f\left(x_{n}\right)-p\right\|^{2} \\
\leq & \left\|x_{n}-p\right\|^{2}+\beta_{n}\left\|f\left(x_{n}\right)-p\right\|^{2} .
\end{aligned}
$$

Since $\sum_{n=0}^{\infty} \beta_{n}<\infty$ and $\left\{f\left(x_{n}\right)\right\}$ is bounded, we obtain $\sum_{n=0}^{\infty} \beta_{n}\left\|f\left(x_{n}\right)-p\right\|^{2}<\infty$. Utilizing Lemma 2.14, we conclude that $\lim _{n \rightarrow \infty}\left\|x_{n}-p\right\|$ exists. Furthermore, it follows from (3.24) that for all $e \geq 0$,

$$
\begin{aligned}
& \left(1-\alpha_{n}\right) \sigma_{n}\left(1-\sigma_{n}\right)\left\|x_{n}-G x_{n}\right\|^{2}+\alpha_{n}\left(1-\alpha_{n}\right)\left\|x_{n}-W_{n} z_{n}\right\|^{2} \\
& \quad \leq\left\|x_{n}-p\right\|^{2}-\left\|x_{n+1}-p\right\|^{2}+\beta_{n}\left\|f\left(x_{n}\right)-p\right\|^{2} .
\end{aligned}
$$

Since $\beta_{n} \rightarrow 0,0<\liminf _{n \rightarrow \infty} \alpha_{n} \leq \lim \sup _{n \rightarrow \infty} \alpha_{n}<1$ and

$$
0<\liminf _{n \rightarrow \infty} \sigma_{n} \leq \limsup _{n \rightarrow \infty} \sigma_{n}<1,
$$


we deduce from (3.25) that

$$
\lim _{n \rightarrow \infty}\left\|x_{n}-G x_{n}\right\|=0 \quad \text { and } \quad \lim _{n \rightarrow \infty}\left\|x_{n}-W_{n} z_{n}\right\|=0 .
$$

It immediately follows that

$$
\lim _{n \rightarrow \infty}\left\|z_{n}-x_{n}\right\|=\lim _{n \rightarrow \infty}\left(1-\sigma_{n}\right)\left\|G x_{n}-x_{n}\right\|=0 .
$$

Note that

$$
\left\|x_{n}-W_{n} x_{n}\right\| \leq\left\|x_{n}-W_{n} z_{n}\right\|+\left\|W_{n} z_{n}-W_{n} x_{n}\right\| \leq\left\|x_{n}-W_{n} z_{n}\right\|+\left\|z_{n}-x_{n}\right\| .
$$

Thus, from (3.26) and (3.27) we have

$$
\lim _{n \rightarrow \infty}\left\|x_{n}-W_{n} x_{n}\right\|=0 .
$$

Also, observe that

$$
\left\|W x_{n}-x_{n}\right\| \leq\left\|W x_{n}-W_{n} x_{n}\right\|+\left\|W_{n} x_{n}-x_{n}\right\| .
$$

From [52, Remark 2.2] (see also [53, Remark 3.1]), we have

$$
\lim _{n \rightarrow \infty}\left\|W x_{n}-W_{n} x_{n}\right\|=0 .
$$

This implies immediately that

$$
\lim _{n \rightarrow \infty}\left\|W x_{n}-x_{n}\right\|=0
$$

Now, let us show that $\omega_{w}\left(x_{n}\right) \subset F$ (see (2.1)). Indeed, let $\bar{x} \in \omega_{w}\left(x_{n}\right)$. Then there exists a subsequence $\left\{x_{n_{k}}\right\}$ of $\left\{x_{n}\right\}$ such that $x_{n_{k}} \rightarrow \bar{x}$. Since $x_{n}-W x_{n} \rightarrow 0$ and $x_{n}-G x_{n} \rightarrow 0$, by Lemma 2.15, we know that $\bar{x} \in \operatorname{Fix}(W)$ and $\bar{x} \in \operatorname{Fix}(G)$. Thus, $\bar{x} \in \operatorname{Fix}(W) \cap \operatorname{Fix}(G)=F$ according to Lemmas 1.1 and 2.11 .

Finally, let us show that $\omega_{w}\left(x_{n}\right)$ is a singleton. Indeed, let $\left\{x_{m_{l}}\right\}$ be another subsequence of $\left\{x_{n}\right\}$ such that $x_{m_{l}} \rightarrow \hat{x}$. Then $\hat{x}$ also lies in $F$. If $\bar{x} \neq \hat{x}$, by Opial's property of $H$, we reach the following contradiction:

$$
\begin{aligned}
\lim _{n \rightarrow \infty}\left\|x_{n}-\bar{x}\right\| & =\lim _{k \rightarrow \infty}\left\|x_{n_{k}}-\bar{x}\right\| \\
& <\lim _{k \rightarrow \infty}\left\|x_{n_{k}}-\hat{x}\right\|=\lim _{l \rightarrow \infty}\left\|x_{m_{l}}-\hat{x}\right\| \\
& <\lim _{l \rightarrow \infty}\left\|x_{m_{l}}-\bar{x}\right\|=\lim _{n \rightarrow \infty}\left\|x_{n}-\bar{x}\right\| .
\end{aligned}
$$

This implies that $\omega_{w}\left(x_{n}\right)$ is a singleton. Consequently, $\left\{x_{n}\right\}$ converges weakly to a point in $F$.

Remark 3.1 Our Theorem 3.1 improves, extends, supplements and develops Ceng et al. [4, Theorem 3.3], Cai and Bu [5, Theorem 3.1] and Ceng and Yao [2, Theorem 3.1] in the following aspects. 
(i) The problem of finding a point $q \in \bigcap_{i=0}^{\infty} \operatorname{Fix}\left(T_{i}\right) \cap \Omega$ in our Theorem 3.1 is more general and more subtle than the problem of finding a point $q \in \bigcap_{i=0}^{\infty} \operatorname{Fix}\left(T_{i}\right)$ in $[4$, Theorem 3.3], and the problem of finding a point $q \in \operatorname{Fix}(T)$ in [2, Theorem 3.1].

(ii) The iterative scheme in [4, Theorems 3.3] is extended to develop the iterative scheme (3.1) of our Theorem 3.1 by virtue of the iterative schemes of [5, Theorem 3.1] and [2, Theorem 3.1]. The iterative scheme (3.1) of our Theorem 3.1 is more advantageous and more flexible than the iterative schemes of [2, Theorem 3.1] and [4, Theorem 3.3] because it can be applied to solving two problems (i.e., GSVI (1.1), fixed point problem of infinitely many nonexpansive mappings) and involves several parameter sequences $\left\{\sigma_{n}\right\},\left\{\alpha_{n}\right\}$ and $\left\{\beta_{n}\right\}$.

(iii) Our Theorem 3.1 extends and generalizes Ceng and Yao [2, Theorem 3.1] from a nonexpansive mapping to a countable family of nonexpansive mappings, and Ceng and Yao [4, Theorems 3.3] to the setting of infinitely many nonexpansive mappings and GSVI (1.1) for two strictly pseudocontractive and strongly accretive mappings. In the meantime, our Theorem 3.1 drops the following restrictions in Cai and $\mathrm{Bu}$ [5, Theorem 3.1]:

Assume that $\sum_{n=1}^{\infty} \sup _{x \in D}\left\|T_{n+1} x-T_{n} x\right\|<\infty$ for any bounded subset $D$ of $C$, and let $T$ be a mapping of $C$ into $X$ defined by $T x=\lim _{n \rightarrow \infty} T_{n} x$ for all $x \in C$ and suppose that $\operatorname{Fix}(T)=\bigcap_{n=1}^{\infty} \operatorname{Fix}\left(T_{n}\right)$.

(iv) The iterative scheme (3.1) in our Theorem 3.1 is very different from every one in [4, Theorem 3.3], [5, Theorem 3.1] and [2, Theorem 3.1] because the mapping $T_{n}$ in [5, Theorem 3.1] and the mapping $T$ in [2, Theorem 3.1] are replaced by the same $W$-mapping $W_{n}$ in the iterative scheme (3.1) of our Theorem 3.1, and (3.1) in our Theorem 3.1 is threestep Mann iterations for finding a point $q \in \bigcap_{i=0}^{\infty} \operatorname{Fix}\left(T_{i}\right) \cap \Omega$ in comparison with two-step Mann iterations for finding a point $q \in \bigcap_{i=0}^{\infty} \operatorname{Fix}\left(T_{i}\right)$ in [4, Theorem 3.3].

(v) Cai and Bu's proof in [5, Theorem 3.1] depends on the argument techniques in [6], the inequality in 2-uniformly smooth Banach spaces (see Lemma 1.1) and the inequality in smooth and uniform convex Banach spaces (see Proposition 1.1). However, the proof of our Theorem 3.1 does not depend on the argument techniques in [6], the inequality in 2-uniformly smooth Banach spaces (see Lemma 1.1), and the inequality in smooth and uniform convex Banach spaces (see Proposition 1.1). It depends only on the inequality in uniform convex Banach spaces (see Lemma 2.13 in Section 2 of this paper), the properties of reflexive Banach space having a weakly continuous duality map $J_{\varphi}$ with gauge $\varphi$, and the properties of the $W$-mapping (see Lemmas 2.6-2.7 and 2.10-2.11 in Section 2 of this paper).

(vi) The assumption of the uniformly convex and 2-uniformly smooth Banach space $X$ in [5, Theorem 3.1] is weakened to the one of the uniformly convex Banach space $X$ which either has a weakly continuous duality map $J_{\varphi}$ with gauge $\varphi$ or is uniformly smooth in our Theorem 3.1. Moreover, our Theorem 3.1 shows that the assumption of the uniformly smooth Banach space $X$ in [2, Theorem 3.1] can be replaced by the assumption of the uniformly convex Banach space $X$ having a weakly continuous duality map $J_{\varphi}$ with gauge $\varphi$ in our Theorem 3.1. It is worth emphasizing that there is no assumption on the convergence of parameter sequences $\left\{\alpha_{n}\right\},\left\{\beta_{n}\right\}$ and $\left\{\sigma_{n}\right\}$ to the zero in our Theorem 3.1.

Competing interests

The authors declare that they have no competing interests. 


\section{Author details}

'Department of Mathematics, Shanghai Normal University, Shanghai, 200234, China. ${ }^{2}$ Scientific Computing Key Laboratory of Shanghai Universities, Shanghai, 200234, China. ${ }^{3}$ Center for Fundamental Science, Kaohsiung Medical University, Kaohsiung, 807, Taiwan.

\section{Acknowledgements}

The first author was partially supported by the National Science Foundation of China (11071169), Innovation Program of Shanghai Municipal Education Commission (09ZZ133) and Ph.D. Program Foundation of Ministry of Education of China (20123127110002). The second author was partially supported by a grant from NSC 102-2115-M-037-001.

\section{Received: 20 May 2013 Accepted: 27 September 2013 Published: 13 Nov 2013}

\section{References}

1. Yao, Y, Chen, R, Yao, JC: Strong convergence and certain control conditions for modified Mann iteration. Nonlinear Anal. 68, 1687-1693 (2008)

2. Ceng, LC, Yao, JC: Relaxed viscosity approximation methods for fixed point problems and variational inequality problem. Nonlinear Anal. 69, 3299-3309 (2008)

3. O'Hara, JG, Pillay, P, Xu, HK: Iterative approaches to convex feasibility problems in Banach spaces. Nonlinear Anal. 64 2022-2042 (2006)

4. Ceng, LC, Wong, NC, Yao, JC: Strong and weak convergence theorems for an infinite family of nonexpansive mappings and applications. Fixed Point Theory Appl. 2012, 117 (2012)

5. Cai, G, Bu, SQ: Convergence analysis for variational inequality problems and fixed point problems in 2-uniformly smooth and uniformly convex Banach spaces. Math. Comput. Model. 55, 538-546 (2012)

6. Ceng, LC, Wang, CY, Yao, JC: Strong convergence theorems by a relaxed extragradient method for a general system of variational inequalities. Math. Methods Oper. Res. 67, 375-390 (2008)

7. Verma, RU: On a new system of nonlinear variational inequalities and associated iterative algorithms. Math. Sci. Res. Hot-Line 3(8), 65-68 (1999)

8. Lions, JL, Stampacchia, G: Variational inequalities. Commun. Pure Appl. Math. 20, 493-512 (1967)

9. Korpelevich, GM: An extragradient method for finding saddle points and for other problems. Ėkon. Mat. Metody 12 747-756 (1976)

10. Facchinei, F, Pang, JS: Finite-Dimensional Variational Inequalities and Complementarity Problems, vol. I. Springer, New York (2003)

11. Facchinei, F, Pang, JS: Finite-Dimensional Variational Inequalities and Complementarity Problems, vol. II. Springer, New York (2003)

12. Iusem, AN, Svaiter, BF: A variant of Korpelevich's method for variational inequalities with a new search strategy. Optimization 42, 309-321 (1997)

13. Ceng, LC, Yao, JC: An extragradient-like approximation method for variational inequality problems and fixed point problems. Appl. Math. Comput. 190, 205-215 (2007)

14. Solodov, MV, Svaiter, BF: A new projection method for variational inequality problems. SIAM J. Control Optim. 37 , 765-776 (1999)

15. Censor, Y, Gibali, A, Reich, S: Two extensions of Korpelevich's extragradient method for solving the variational inequality problem in Euclidean space. Technical report (2010)

16. Zeng, LC, Yao, JC: Strong convergence theorem by an extragradient method for fixed point problems and variational inequality problems. Taiwan. J. Math. 10, 1293-1303 (2006)

17. liduka, H, Takahashi, W: Strong convergence theorems for nonexpansive mappings and inverse-strongly monotone mappings. Nonlinear Anal. 61, 341-350 (2005)

18. Nadezhkina, N, Takahashi, W: Weak convergence theorem by an extragradient method for nonexpansive mappings and monotone mappings. J. Optim. Theory Appl. 128, 191-201 (2006)

19. Ceng, LC, Ansari, QH, Yao, JC: An extragradient method for solving split feasibility and fixed point problems. Comput. Math. Appl. 64(4), 633-642 (2012)

20. Ceng, LC, Teboulle, M, Yao, JC: Weak convergence of an iterative method for pseudomonotone variational inequalities and fixed point problems. J. Optim. Theory Appl. 146, 19-31 (2010)

21. Ceng, LC, Ansari, QH, Yao, JC: Relaxed extragradient methods for finding minimum-norm solutions of the split feasibility problem. Nonlinear Anal. 75(4), 2116-2125 (2012)

22. Ceng, LC, Ansari, QH, Yao, JC: Relaxed extragradient iterative methods for variational inequalities. Appl. Math. Comput. 218, 1112-1123 (2011)

23. Aoyama, K, Kimura, Y, Takahashi, W, Toyoda, T: Approximation of common fixed points of a countable family of nonexpansive mappings in Banach spaces. Nonlinear Anal. 67, 2350-2360 (2007)

24. Verma, RU: Projection methods, algorithms and a new system of nonlinear variational inequalities. Comput. Math. Appl. 41, 1025-1031 (2001)

25. Ceng, LC, Ansari, QH, Wong, NC, Yao, JC: An extragradient-like approximation method for variational inequalities and fixed point problems. Fixed Point Theory Appl. 2011, 22 (2011)

26. Ceng, LC, Hadjisavvas, N, Wong, NC: Strong convergence theorem by a hybrid extragradient-like approximation method for variational inequalities and fixed point problems. J. Glob. Optim. 46, 635-646 (2010)

27. Ceng, LC, Guu, SM, Yao, JC: Finding common solutions of a variational inequality, a general system of variational inequalities, and a fixed-point problem via a hybrid extragradient method. Fixed Point Theory Appl. 2011, Article ID $626159(2011)$

28. Ceng, LC, Petrusel, A: Krasnoselski-Mann iterations for hierarchical fixed point problems for a finite family of nonself mappings in Banach spaces. J. Optim. Theory Appl. 146, 617-639 (2010)

29. Yao, Y, Liou, YC, Kang, SM, Yu, YL: Algorithms with strong convergence for a system of nonlinear variationa inequalities in Banach spaces. Nonlinear Anal. 74(17), 6024-6034 (2011)

30. Aoyama, K, liduka, H, Takahashi, W: Weak convergence of an iterative sequence for accretive operators in Banach spaces. Fixed Point Theory Appl. 2006, Article ID 35390 (2006) 
31. Chen, RD, Zhu, ZC: Viscosity approximation of fixed points for nonexpansive and $m$-accretive operators. Fixed Point Theory Appl. 2006, Article ID 81325 (2006)

32. Ceng, LC, Xu, HK, Yao, JC: Strong convergence of an iterative method with perturbed mappings for nonexpansive and accretive operators. Numer. Funct. Anal. Optim. 29(3-4), 324-345 (2008)

33. Kamimura, S, Takahashi, W: Weak and strong convergence of solutions to accretive operator inclusions and applications. Set-Valued Anal. 8, 361-374 (2000)

34. Xu, HK: Inequalities in Banach spaces with applications. Nonlinear Anal. 16, 1127-1138 (1991)

35. Kamimura, S, Takahashi, W: Strong convergence of a proximal-type algorithm in a Banach space. SIAM J. Optim. 13 938-945 (2002)

36. Takahashi, Y, Hashimoto, K, Kato, M: On sharp uniform convexity, smoothness, and strong type, cotype inequalities. J. Nonlinear Convex Anal. 3, 267-281 (2002)

37. Browder, FE: Convergence theorems for sequences of nonlinear operators in Banach spaces. Math. Z. 100, 201-225 (1967)

38. Zeng, LC, Lee, GM, Wong, NC: Ishikawa iteration with errors for approximating fixed points of strictly pseudocontractive mappings of Browder-Petryshyn type. Taiwan. J. Math. 10, 87-99 (2006)

39. Takahashi, W, Toyoda, M: Weak convergence theorems for nonexpansive mappings and monotone mappings. J. Optim. Theory Appl. 118, 417-428 (2003)

40. liduka, $\mathrm{H}$, Takahashi, W, Toyoda, M: Approximation of solutions of variational inequalities for monotone mappings. Panam. Math. J. 14, 49-61 (2004)

41. $\mathrm{Xu}, \mathrm{HK}, \mathrm{Kim}, \mathrm{TH}$ : Convergence of hybrid steepest-descent methods for variational inequalities. J. Optim. Theory Appl. 119(1), 185-201 (2003)

42. Takahashi, W: Nonlinear Functional Analysis. Yokohama Publisher, Yokohama (2000)

43. Reich, S: Weak convergence theorems for nonexpansive mappings in Banach spaces. J. Math. Anal. Appl. 67, 274-276 (1979)

44. Xu, HK: Viscosity approximation methods for nonexpansive mappings. J. Math. Anal. Appl. 298, $279-291$ (2004)

45. Lim, TC, Xu, HK: Fixed point theorems for asymptotically nonexpansive mappings. Nonlinear Anal. 22, 1345-1355 (1994)

46. Opial, Z: Weak convergence of successive approximations for nonexpansive mappings. Bull. Am. Math. Soc. 73, 591-597 (1967)

47. Van Dulst, D: Equivalent norms and the fixed point property for nonexpansive mappings. J. Lond. Math. Soc. 25 , 139-144 (1982)

48. Bruck, RE: Properties of fixed point sets of nonexpansive mappings in Banach spaces. Trans. Am. Math. Soc. 179 251-262 (1973)

49. Shimoji, K, Takahashi, W: Strong convergence to common fixed points of infinite nonexpansive mappings and applications. Taiwan. J. Math. 5, 387-404 (2001)

50. Suzuki, T: Strong convergence of Krasnoselskii and Mann's type sequences for one parameter nonexpansive semigroups without Bochner integrals. J. Math. Anal. Appl. 305, 227-239 (2005)

51. Tan, KK, Xu, HK: Approximating fixed points of nonexpansive mappings by the Ishikawa iteration process. J. Math. Anal. Appl. 178, 301-308 (1993)

52. Ceng, LC, Yao, JC: Hybrid viscosity approximation schemes for equilibrium problems and fixed point problems of infinitely many nonexpansive mappings. Appl. Math. Comput. 198, 729-741 (2008)

53. Yao, YH, Liou, YC, Yao, JC: Convergence theorem for equilibrium problems and fixed point problems of infinitely many nonexpansive mappings. Fixed Point Theory Appl. 2007, Article ID 64363 (2007)

10.1186/1029-242X-2013-539

Cite this article as: Ceng and Wen: Three-step Mann iterations for a general system of variational inequalities and an infinite family of nonexpansive mappings in Banach spaces. Journal of Inequalities and Applications 2013, 2013:539

\section{Submit your manuscript to a SpringerOpen ${ }^{\circ}$ journal and benefit from:}

- Convenient online submission

Rigorous peer review

- Immediate publication on acceptance

- Open access: articles freely available online

- High visibility within the field

- Retaining the copyright to your article

Submit your next manuscript at $>$ springeropen.com 